\title{
Determination of the Weight Average Molecular Weight of Two Poly (Ethylene Oxides), SRM 1923 and SRM 1924
}

Charles M. Guttman

John R. Maurey

U.S. DEPARTMENT OF COMMERCE

Technology Administration

National Institute of Standards

and Technology

Materials Science \& Engineering Lab

Polymers Division

Gaithersburg, MD 20899

QC 


\section{Determination of the Weight Average Molecular Weight of Two Poly (Ethylene Oxides), SRM 1923 and SRM 1924}

Charles M. Guttman John R. Maurey

U.S. DEPARTMENT OF COMMERCE Technology Administration National Institute of Standards and Technology

Materials Science \& Engineering Lab Polymers Division

Gaithersburg, MD 20899

February 1994

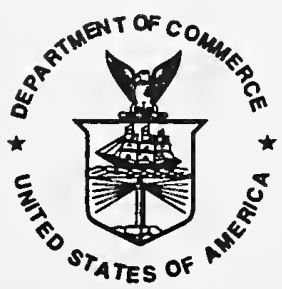

U.S. DEPARTMENT OF COMMERCE Ronald H. Brown, Secretary

TECHNOLOGY ADMINISTRATION Mary L. Good, Under Secretary for Technology

NATIONAL INSTITUTE OF STANDARDS AND TECHNOLOGY

Aratl Prabhakar, Director 
Determination of the Weight Average Molecular Weight of Two Poly(ethylene oxides), SRM 1923 and SRM 1924

by C. M. Guttman and J. R. Maurey

Polymers Division

N.I.S.T.

Gaithersburg, MD 20899

Certain commercial materials and equipment are identified in this paper in order to specify adequately the experimental procedure. In no case does such identification imply recommendation or endorsement by the National Institute of Standards and Technology, nor does it imply necessarily the best available for the purpose.

A final report prepared for the sponsors, standard Reference Materials Program 


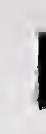

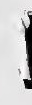

। 


\section{ABSTRACT}

The characterization of two narrow molecular weight distribution poly (ethylene oxide) standard reference materials, SRM 1923 and SRM 1924, is described. The weight-average molecular weight of SRM 1923 by light scattering was determined to be $26.9 \times 10^{3} \mathrm{~g}$ mole-1 with a sample standard deviation of $0.87 \times 10^{3} \mathrm{~g} \mathrm{~mole} \mathrm{e}^{-1}$, based on 3 degrees of freedom. A combined expanded uncertainty of $2.2 \times 10^{3} \mathrm{~g} \mathrm{~mole}^{-1}$ is estimated for this determination. The weight-average molecular weight of SRM 1924 by light scattering was determined to be $120.9 \times 10^{3} \mathrm{~g}$ mole $\mathrm{e}^{-1}$ with a sample standard deviation of $1.0 \times 10^{3} \mathrm{~g} \mathrm{~mole}$, based on 3 degrees of freedom. expanded uncertainty of $9.0 \times 10^{3} \mathrm{~g}$ mole $\mathrm{e}^{-1}$ is estimated for this determination. 
No standard reference materials (SRM's) are presently available for water-soluble high polymers. Water soluble polymers are industrially important in such areas as adhesives, coatings, paints, lubricants, and oil resistant plastics. The need for standards for these materials has been noted by the Polymers Division Assessment Panel, during staff visits to industrial characterization laboratories, and in the responses to market surveys.

By far, the most pressing need for water-soluble, molecular-weight polymer SRM's is calibration standards for aqueous size exclusion chromatography (SEC). For this purpose, samples of narrow molecular weight distribution polyethylene oxides have been chosen as proposed standards. The polyethylene oxide SRM's should be usable on most aqueous SEC columns without special column conditioning.

This report describes the certification of the weight average molecular weight of two poly (ethylene oxides), SRM 1923 and SRM 1924 .

2.0 Preparation, Bottling, and Handling of SRM 1923 and SRM 1924

\subsection{Preparation}

The molecular weight standards, SRM 1923 and SRM 1924, are narrow molecular weight poly (ethylene oxides) which can be used for SEC calibration.

Both polyethylene oxide standards were prepared for us by Polymer Labs, England. SRM 1923, the low molecular weight standard, was received as a light fluffy powder. SRM 1924, the high molecular weight standard came as foamed disks.

\subsubsection{Bottling and Sampling of SRM 1923}

The material was given to standard Reference Materials Program office (SRMP) for bottling. A total of 268 samples, about $0.2 \mathrm{~g}$ each, were bottled under dry argon in amber vials. The entire set of samples was divided into 8 subsets. One vial was randomly selected from each subset for homogeneity testing. Testing was also done on the first and last vial of the bottling. In the following, the containers holding SRM 1923 or SRM 1924 will be referred to as vials.

\section{2 .2 Bottling and Sampling of SRM 1924}

The material came in the form of rigid foam disks. Samples from the original disks were cut with clean scissors and checked for disk to disk homogeneity by SEC, as describe below. No disk to disk variability was found. The material was then delivered to SRMP for bottling. A total of 294 samples, about $0.2 \mathrm{~g}$ each, were bottled under dry argon in amber vials. The entire set of samples was divided into 15 subsets. One vial was randomly selected from each subset for homogeneity testing. Testing was also done on the first and last vial of the bottling. 


\subsection{Homogeneity Testing on SRM 1923 and SRM 1924}

This testing was done using size Exclusion Chromatography (SEC). In this study a Waters 150-C AL/GPC Liquid Chromatograph with a refractive index (RI) detector and a single Tosoh TSK-Gel G5000PW $30 \mathrm{~cm} 10 \mathrm{ng} 7.5 \mathrm{~mm}$ ID mixed bed aqueous SEC column was used. The chromatographs were taken at $0.5 \mathrm{cc} / \mathrm{min}$ flow rate. The injector and column compartment of the Waters 150-C were controlled at $30^{\circ} \mathrm{C}$ for all measurements. Distilled water which was run through a Culligan Aqua-summa Reagent water purifier was used as the solvent. Ethylene glycol, $0.3 \mathrm{~g} / \mathrm{L}$, was added to the solvent, as a SEC pump marker for all measurements.

The polyethylene oxide samples were dissolved in the solvent at concentration of approximately $1.0 \mathrm{~g} / \mathrm{L}$. Each bottle was shaken at frequent intervals to aid the dissolution. The solutions were filtered through 0.22 micron Millex-GV disposable filters. Chromatograms were then run on these solutions.

SEC chromatograms were normalized to unit peak height and compared by overlaying to determine if there were visible differences outside the noise. We, furthermore, compared chromatograms more quantitatively using a statistical technique called the match factor discussed in the next section.

The chromatograms from different solutions of SRM 1923 superimpose on each other. Figure 1 shows some of these chromatograms. Chromatograms from different solutions of SRM 1924 also superimpose on each other. However, small time shifts are seen between some chromatograms run on different days in contrast to chromatograms run on the same day which show no visible differences. An example of chromatograms run on the same day is given in figure 2. Differences between chromatograms run on different days is seen in figure 3. Figure 3 can be made to look like figure 2 by shifting the time scale on one of the chromatograms by .02 minutes. This is about the time between data collection points in our data collection program. We should point out that the pump position peak of ethylene glycol does not change at all.

However, the same sample was often run on two different days and the data from these identical samples show the same shift in the same direction. Consequently, we attribute the shift to a column or instrument problem and not to a material problem. Thus we consider that the material is homogeneous.

\subsection{Statistical Method to Compare Chromatograms}

Several statistical techniques are available for comparison of chromatograms. For chromatograms containing only a small amount of fine structure, the correlation coefficient [1] of the signals from the two chromatograms gives a good idea of agreement between two chromatograms. This quantity of comparison, often called the match factor when comparing two chromatograms, is defined as [2] 
Match Factor $=10^{3}\{\Sigma x * y-(\Sigma x * \Sigma y) / n\}^{2} /\left[\left\{\Sigma x^{2}-\Sigma x * \Sigma x / n\right\}\left\{\Sigma y^{2}-\Sigma y * \Sigma y / n\right\}\right] \cdot$

The values $x$ and $y$ are the measured signal in the first and second chromatogram respectively at the same time in the chromatogram; $\mathrm{n}$ is the number of data points. Sums are taken over all data points.

At the extremes, a match factor of 0 indicates no match and 1000 indicates identical chromatogram. Generally, values above 990 indicate that the chromatograms are similar [2].

\subsubsection{Match Factor for SRM 1923}

Data from the match factor as applied to various SEC chromatograms of SRM 1923 are given in table 1 and table 2. Samples marked "bulk" are solutions of SRM 1923 from a bottle containing about 5 grams of SRM 1923 reserved by us for future use. All chromatograms were compared using the match factor against the first chromatogram in the list.

In Table 1, chromatograms numbered 6355 to 6357 are reinjections of the solution used in run 6354 and their values show the optimum match factor expected for identical repeated injections of the same sample. These all give match factors greater than 998. Also in table 1 we show chromatograms run on different solutions made from the same vial to see the effect of within vial variation. These give match factors as low as 997.

In Table 2 we present data for match factors for solutions made from different vials. This data indicates the vial to vial variation is about the same as the within vial variation except for one run, run 6364 from vial 188. Two additional solutions from this same vial were run and compared to run 6354. These solutions gave match factors of 997.9 and 998.4. These are close to those obtained for the other solutions and that obtained for the repeated injection experiments. Thus, we conclude that the match factor analysis agrees with our visual observation of the chromatograms that the bottled material of SRM 1923 is homogeneous.

\subsubsection{Match Factor for SRM 1924}

Table 3 shows the match factor for chromatograms from different solutions made up from one sample of SRM 1924. The match factors are all above 990. These data show the range of match factors expected for solutions made from the same sample vial. We should point out the match factor from the data from vial 294 show the effect of the 0.02 minute shift discussed above. These data show the most deviation from 1000 .

Table 4 shows the match factors of the various solutions from vials of SRM 1924 against one chromatogram for SRM 1924 from vial 73. These match factors all occur in a range similar to that in Table 3 showing that the chromatograms are identical.

Thus, we conclude that there is no vial-to-vial variation in the SEC for this material. 


\subsection{Aging studies on SRM 1923 in water by SEC}

McGary has discussed the degradation of polyethylene oxide in water both with and without light [3]. We, therefore, were concerned that the polymer would degrade during the light scattering experiment. However, a SEC study using the RI detector showed that solutions of SRM 1923 kept in the laboratory for as long as four days exposed to light exhibited no change in the main SEC peak. McGary's study showed that PEO prepared in different ways showed different degradation rates and that the presence of low salt concentrations in solution greatly affected the degradation rate. We used low conductivity water in all our work.

Ten solutions of SRM 1923 in water were kept in the laboratory unprotected from light and oxygen for as long as three weeks. Two of the ten solutions showed an additional broad high molecular weight peak at around 130,000 daltons. We do not think this is degradation since there is no apparent shift of the main peak towards low molecular weights, no broadening of the central peak, and no new low molecular weight peak. This high molecular weight peak may be a result of association of the polymer. Strazielle [18] described the behavior of such aggregates of poly(ethylene oxides) in solution with different solvents, including water and methanol. When such a high molecular weight peak was detected in the chromatograms of a sample, subsequent samples were heated at $50^{\circ} \mathrm{C}$ for 1 hour prior to SEC runs. The peak did not occur in chromatograms of these samples. Furthermore, the high molecular weight peak appeared distinctly remote from the main peak in the chromatograms and should not effect the SEC calibration.

The above discussion leads to the conclusion that degradation during the light scattering should be of no concern since fresh solutions are prepared and light scattering measurements are made on the same day.

We suggest, however, that fresh solutions of the standard be made up before each SEC calibration run to avoid any possibility of degradation or association.

\subsection{Estimate of $\mathrm{M}_{\mathrm{w}} / \mathrm{M}_{\mathrm{n}}$ for SRM 1923 and SRM 1924 by SEC}

The SEC was run on SRM 1923 and SRM 1924, dissolved in water, as described in section 3.1. The aqueous SEC columns were calibrated with polyethylene oxide fractions from Polymer Labs and with SRM 1923 and SRM 1924 using the MW obtained in section 5.0. The calibration with the standards from Polymers Labs and with SRM 1923 and SRM 1924 followed the same curve. In fact, a calibration curve derived from the two SRM's alone would have been adequate for the estimate of the $M_{w} / M_{n}$ ratio.

$M_{w} / M_{n}$ estimated by this method was 1.06 for SRM 1923 and 1.04 for SRM 1924. The $M_{w} / M_{n}$ estimated in this way is an overestimate since the calculation assumes that all broadening is from the molecular weight distribution and it neglects chromatographic broadening. 
5.0 Determination of Molecular Weight of SRM 1923 and SRM 1924 by Light scattering

\subsection{Light scattering on the Poly(ethylene oxide) standard}

\subsubsection{Solution and Solvent Preparation}

The poly (ethylene oxide) (PEO) samples were weighed on an analytical balance with $0.01 \mathrm{mg}$ resolution in mass indication. Buoyancy corrections were applied. The maximum uncertainty in sample solute weight was 1 part in 1000. It was experimentally determined, as described in the following paragraphs, that contact with the ambient atmosphere of the laboratory had no measurable effect on the PEO sample weight within a time interval required to weigh a sample. The SRM 1923 powder samples were weighed on small pieces of powder paper. Required approximate amounts of SRM 1924 porous disk sample were cut with a pair of clean scissors and placed directly on the pan of the analytical balance.

The response of the balance was tested by weighing a $50 \mathrm{mg}$ standard balance weight, closely comparable with the weights of the PEO samples used in solution preparation. The balance appeared to arrive at equilibrium weight within 1 minute after the $50 \mathrm{mg}$ standard weight had been loaded onto the pan, and maintained the same indicated apparent weight within $\pm 0.00001 \mathrm{~g}$ random variation.

Samples of SRM 1923 and SRM 1924 were subjected to special drying in weighing bottles to test the stability of sample weight during weighing. The PEO samples were maintained under full vacuum in an oven at $45^{\circ} \mathrm{C}$ overnight before being weighed. The apparent weight of each sample was monitored on the balance for 20 minutes after being loaded onto the balance pan from its weighing bottle. The SRM 1923 sample apparent weight reached initial equilibrium within 1 minute, and drifted gradually downward by as much as $0.00005 \mathrm{~g}$ during the remainder of the $20 \mathrm{~min}$ interval. Sample weight loss under these conditions is considered unlikely, and it is more probable that the weight loss is attributable to random changes in apparent weight of the weighing paper. Experience with weighing the same piece of powder paper many times has demonstrated that its apparent weight varies $\sim 0.1 \mathrm{mg}$, most likely due to the electrostatic effects. The SRM 1924 sample was weighed directly on the pan without using powder paper. Its apparent weight also reached initial equilibrium within the first minute, and thereafter showed a random variation within a range of only $\sim 0.00002 \mathrm{~g}$ for the remainder of the $20 \mathrm{~min}$. interval.

Mallinckrodt methanol, analytical reagent, was used as the solvent without modification. Methanol is hygroscopic and its refractive index increased from contact with the ambient atmosphere of the laboratory. Therefore, a glove box containing dry nitrogen was used when adding solvent to bottles containing PEO samples. The amount of solvent added was determined gravimetricaliy on a top loading balance with $0.01 \mathrm{~g}$ resolution in indication, and this limit in resolution was accepted as the uncertainty in mass of solvent component added to form each solution. Buoyancy corrections for dry nitrogen were applied. 
The PEO was dissolved in the solvent by placing the bottles in an aluminum block dry bath at $50^{\circ} \mathrm{C}$ and agitating with manual swirling. This process would obtain complete solution formation with SRM 1923 within 5 minutes, and the bottles were maintained in the dry bath for approximately one quarter hour. The SRM 1924 dissolved somewhat more slowly, partly due to its different bulk form. Thus, the bottles of SRM 1924 in methanol were maintained in the dry bath for approximately one hour. The partial specific volume for polyethylene glycol in methanol tabulated as 0.785 $\mathrm{cm}^{3} \mathrm{~g}^{-1}$ by Elias [4], and methanol density versus temperature tabulated from several sources by Riddick and Bunger [5], were applied to compute solution concentrations at $25.0^{\circ} \mathrm{C}$. No weight loss was attributed to the heating process.

After the solutions had cooled to ambient temperature, solvent and solution samples were filtered into light scattering cells in a dry nitrogen environment contained inside a glove bag. The solvent and solution samples were filtered through filtering assemblies with double thicknesses of Millipore Fluoropore membrane with $0.2 \mu \mathrm{m}$ average pore size.

\section{1 .2 Determination of $\mathrm{dn} / \mathrm{dc}$}

The differential refractive index for SRM 1923 and SRM 1924 in methanol at $25^{\circ} \mathrm{C}$ for light of $632.8 \mathrm{~nm}$ wavelength was determined using a LDC/Milton Roy Chromatix KMX-16 differential refractometer. The differential refractometer was calibrated against aqueous NaCl solutions.

Refractive increments versus concentration for several aqueous electrolyte solutions at several wavelengths of light were reported by Kruis [7]. Refractive increments for the same solutions at the $\mathrm{He}-\mathrm{Ne}$ laser wavelength, $\lambda=632.8 \mathrm{~nm}$, have been determined from interpolation of the data in the Kruis tables [8,9]. A cubic equation for these refractive increments as a function of $\mathrm{NaCl}$ concentration in aqueous solution at $25^{\circ}$ is given in the instrument manual, and was used to compute the refractive increments of the aqueous $\mathrm{NaCl}$ solutions prepared as standards in calibrating the differential refractometer.

Mallinckrodt analytical reagent $\mathrm{NaCl}$ was dried in a vacuum oven at $90^{\circ} \mathrm{C}$ for three days in preparation to be used as a calibrant. The dried $\mathrm{NaCl}$ was then maintained in a vacuum desiccator except while taking salt samples to prepare solutions. Distilled water was degassed by boiling and left to cool to ambient temperature overnight in storage bottles tightly capped with zero headspace. The storage bottles had been leached out with several changes of boiling distilled water before being used to contain the degassed distilled water. Both salt and water components of each solution were measured gravimetrically, and atmospheric buoyancy corrections were applied to compute the concentrations as $\mathrm{g} \mathrm{NaCl} / 100 \mathrm{~g}$ $\mathrm{H}_{2} \mathrm{O}$. Measurements in the differential refractometer were conducted on seven solutions ranging in concentration from $0.5 \mathrm{~g} \mathrm{NaCl} / 100 \mathrm{~g} \mathrm{H}_{2} \mathrm{O}$ to 2.0 $g \mathrm{NaCl} / 100 \mathrm{~g} \mathrm{H}_{2} \mathrm{O}$ in intervals of $0.25 \mathrm{~g} \mathrm{NaCl} / 100 \mathrm{~g} \mathrm{H}_{2} \mathrm{O}$. The calculated refractive increments of the solutions were fitted to their average image displacements to generate a linear calibration equation of refractive 
increment versus image displacement, $\mathrm{dn} / \mathrm{dx}$.

Refractive increments between solvent and solutions of PEO in methanol were determined on solutions which had been prepared on the morning of each day during which the measurements were conducted. The solutions were prepared by the procedure describe in section 5.1.1.

Image displacement measurements were conducted on six methanol solutions of SRM 1923 varying in concentration from $0.5 \mathrm{~g} / \mathrm{L}$ to $5 \mathrm{~g} / \mathrm{L}$ at $25^{\circ} \mathrm{C}$. An average was taken from eight individual image displacement measurements for each solvent versus solvent and solution versus solvent. The average image displacement determined for each solution was bracketed by the determination of average solvent versus solvent image displacements before and after that of the solution. The incremental image displacement by each solution was obtained by subtracting the mean of the bracketing solvent average image displacements from the average image displacement by the solution. The refractive increment of each solution was computed by application of the calibration equation to the incremental image displacement of the solution. Linear regression analysis of the refractive increments versus the concentrations of the solutions yielded a differential refractive index, $\mathrm{dn} / \mathrm{dc}=0.1434, \mathrm{~cm}^{3} \mathrm{~g}^{-1}$, for $\mathrm{SRM} 1923$ in methanol with a standard uncertainty $\mathrm{u}=0.0002 \mathrm{~cm}^{3} \mathrm{~g}^{-1}$.

The differential refractive index for SRM 1923 in methanol had also been determined earlier with a different instrument calibration before installing a new laser and realigning the optics. The earlier determination was computed with refractive increments also on six solutions of very nearly the same concentrations used in the determination described in the preceding paragraph. Linear regression analysis of these refractive increments versus solution concentration yielded a differential refractive index, $\mathrm{dn} / \mathrm{dc}=0.1437, \mathrm{~cm}^{3} \mathrm{~g}^{-1}$ for SRM 1923 in methanol, with a standard uncertainty $\mathrm{u}=0.0001_{8} \mathrm{~cm}^{3} \mathrm{~g}^{-1}$.

The agreement between the two determinations appeared to justify combining the data into a single determination with twelve experimental points of refractive increment versus concentration. Linear regression analysis of the twelve points of refractive increment versus concentration, combined from the two experiments, resulted in a differential refractive index of $0.1436_{1}, \mathrm{~cm}^{3} \mathrm{~g}^{-1}$ with a standard uncertainty of $\mathrm{u}=0.0002 \mathrm{~cm}^{3} \mathrm{~g}^{-1}$. A plot of $\Delta \mathrm{n}$ versus $\mathrm{c}$ for these twelve solutions is shown in Figure 4. As will be explained in the following paragraphs, the dn/dc computed from experimental results with all twelve SRM 1923 solutions was used to process the light scattering data from the characterization of both SRM 1923 and SRM 1924.

A determination of the dn/dc for SRM 1924 in methanol was also conducted on three solutions of concentration $2 \mathrm{~g} / \mathrm{L}, 3 \mathrm{~g} / \mathrm{L}$, and $5 \mathrm{~g} / \mathrm{L}$. This limited population determination was conducted for comparison with the results from the determination on SRM 1923 in order to decide whether it would be necessary to conduct a more rigorous separate determination for SRM 1924. Linear regression analysis of the three data points for SRM 
1924 yields a value $\mathrm{dn} / \mathrm{dc}=0.1431_{3} \mathrm{~cm}^{3} \mathrm{~g}^{-1}$ with a standard uncertainty $\mathrm{u}=0.0003_{3}$. The $\Delta \mathrm{n} / \mathrm{c}$ ratios of the SRM 1924 solutions were compared with the $\Delta \mathrm{n} / \mathrm{C}$ ratios of SRM 1923 solutions of corresponding concentration. These results are listed in Table 5. The close agreement between the $\Delta \mathrm{n} / \mathrm{c}$ values of SRM 1923 and SRM 1924 solutions of the same concentration indicates that the $\mathrm{dn} / \mathrm{dc}$ values of the two polymers are not significantly different.

As an additional test, the three data points from the SRM 1924 solutions were added to the twelve points from the SRM 1923 solutions, and the $\mathrm{dn} / \mathrm{dc}$ was recomputed by linear regression analysis of the combined 15 data points of refractive increments versus concentration. This computation yielded a value for $\mathrm{dn} / \mathrm{dc}=0.1434_{6} \mathrm{~cm}^{3} \mathrm{~g}^{-1}$ with a standard uncertainty $u=0.0002 \mathrm{~cm}^{3} \mathrm{~g}^{-1}$. The substantial statistical overlap between the $\mathrm{dn} / \mathrm{dc}$ determined from the twelve SRM 1923 solutions and the dn/dc determined from the fifteen SRM 1923 and SRM 1924 solutions indicates that the dn/dc computed from the SRM 1923 solutions alone has not been significantly changed by adding the data from the SRM 1924 solutions. These observations with the refractive increments versus concentration data from the three solutions of SRM 1924 indicate that the differential refractive index of SRM 1924 in methanol under these conditions is not detectably different from that of SRM 1923. Consequently, the $\mathrm{dn} / \mathrm{dc}$ determination from the twelve SRM 1923 solutions was applied in processing the light scattering data from the characterization of both SRM 1923 and SRM 1924 .

\subsubsection{Refractive Indices of Solvent and calibrant}

The refractive indices of methanol, and of benzene used as the calibrating standard, were derived from those tabulated for the He-Ne laser wavelength at $23^{\circ} \mathrm{C}$ by Kaye and McDaniel [10]. Values for the temperature dependence of the refractive indices, dn/dT, of methanol and benzene were determined from refractive indices of these two solvents tabulated by Riddick and Bunger $[5,6]$ at different temperatures for the $589 \mathrm{~nm}$ wavelength. The resulting calculated values for dn/dT were in close agreement with those tabulated by Johnson and Smith for other spectral wavelengths [11]. These dn/dT coefficients were applied to the refractive indices tabulated at $23^{\circ} \mathrm{C}$ by Kaye and McDaniel to obtain the refractive indices at $25^{\circ} \mathrm{C}$. The resulting refractive indices calculated at $25^{\circ} \mathrm{C}$ and $632.8 \mathrm{~nm}$ wavelength were 1.326 for methanol, and 1.496 for benzene.

\subsubsection{Light Scattering Methods}

Light scattering measurements on the PEO solutions in methanol were made on a Brookhaven Instrument Model BI-200 light scattering apparatus with a 10 milliwatt He-Ne laser light source. Since the laser beam is vertically polarized, and a vertical polarizer is used in the detector optics, we have $v_{v}$ polarization for the scattered light intensity.

The exceptionally high refractive increment between the cell and the 
methanol solvent system caused special problems with the light scattering measurements. The problem of high intensity flare and reflection from the laser beam at the glass-methanol interface in the cell was minimized by using cells with $27 \mathrm{~mm}$ outer diameter (Brookhaven BI-RC27 cells) to remove the intersection of the laser beam with the cell wall as far from the view of the detector optics as possible. The refraction of the laser beam, as it enters the methanol phase inside the cell, necessitated a fine adjustment of the incident beam alignment by the beam focusing and steering lens with a methanol cell placed in the beam. Small eccentricities in the cylindrical geometry of the cells caused variations in light scattering pattern, which were detectable at extreme angles of scattering, within the population of cells. Even with all these precautions, data from angles less than $37^{\circ}$ and greater than $143^{\circ}$ showed deviations from I sin $(\theta)$ of as much as $4 \%$. This optical alignment problem contributed to deviation from ideal scattering intensity versus angle, both symmetric and asymmetric in angle, in I sin( $\theta)$ plots and in the zimm plots. The uncertainties in final molecular weights arising from these effects are discussed in section 5.5.11.

Six solutions of PEO in methanol were prepared for each experiment. SRM 1923 solutions were prepared in a range of concentrations from $0.2 \mathrm{~g} / \mathrm{L}$ to $1.6 \mathrm{~g} / \mathrm{L}$, and SRM 1924 solutions were prepared in concentrations ranging from $0.1 \mathrm{~g} / \mathrm{L}$ to $1.2 \mathrm{~g} / \mathrm{L}$. During any one day the six solutions were prepared, samples were filtered into the cells, and light scattering experiments were conducted. The solutions were stored in the dark except while being used in a light scattering experiment. often light scattering experiments were repeated with the solutions on the day following their preparation, with negligible random changes in the molecular weight values determined.

The temperature was controlled at $25.0^{\circ} \mathrm{C}$ in all experiments with PEO in methanol. In all experiments, the intensity measuring system was calibrated with the intensity of the light scattered from the beam at $90^{\circ}$ angle by a benzene standard cell, and the scattering intensity from each solvent and solution sample was measured at ten angles in the range from $37.5^{\circ}$ to $142.5^{\circ}$.

\subsection{Analysis of Light Scattering Data}

Light scattering data at $V_{v}$ polarization from polymer solutions of concentration $c$ and scattering angle $\theta$ may be analyzed by fitting the scattering signal $I(\theta, c)$ to $[12]$

$$
I(\theta, c)=I(\theta, 0)+c I_{G} /\left\{(\sin \theta) \sum C_{i j} c^{i} \sin ^{2 j}(\theta / 2)\right\} \text {. }
$$

In eqn (1) $I_{G}$ is the scattering signal from the benzene working standard at $\theta=90^{\circ}$.

In order to use eqn (1) for the estimation of molecular parameters, we must first decide how many terms on the right-hand side must be included to provide an adequate fit to the experimental data. The dependence of $c / I_{c}$, where $I_{c}=\sin \theta[I(\theta, c)-I(\theta, 0)] / I_{G}$, upon $c$ and upon 
$\sin ^{2}(\theta / 2)$ reflects solute-solvent interactions and solute size, respectively. Accordingly, preliminary scattering data for SRM 1923 and SRM 1924 were first analyzed as $c / I_{c}$ versus $\sin ^{2}(\theta / 2)$ at constant concentration and versus $c$ at constant scattering angle, to see whether a linear expansion (i.e., retaining only $c_{00}, C_{01}$, and $C_{10}$ ) would provide an adequate fit. The analysis revealed that the linear approximation was adequate at concentrations below $1.6 \mathrm{~g} / \mathrm{L}$ for SRM 1923 and $1.2 \mathrm{~g} / \mathrm{L}$ for SRM 1924. The next higher order terms, $C_{20}$ and $C_{02}$, were included in the final fit to show that the data were consistent with this hypothesis.

Thus we used for the final analysis

$$
\begin{aligned}
& I(\theta, c)=I(\theta, 0)+c I_{G} /\left\{\operatorname { s i n } \theta \left(C_{00}+C_{01} \sin ^{2}(\theta / 2)+\right.\right. \\
& \left.\left.C_{10} c+C_{11} c \sin ^{2}(\theta / 2)+C_{20} c^{2}+C_{02}\left(\sin ^{2}(\theta / 2)\right)^{2}\right)\right\}
\end{aligned}
$$

The coefficients in eqn (2) are related to the weight-average molecular weight $\mathrm{M}_{w}$, molecular mean-square radius of gyration $\mathrm{R}_{\mathrm{G}}{ }^{2}$, and second and third viral coefficients, $A_{2}$ and $A_{3}$, by [12-15]:

$$
\begin{aligned}
\mathrm{M}_{\mathrm{w}} & =\left(\mathrm{K}^{\prime} \mathrm{C}_{00}\right)^{-1} \\
\mathrm{R}_{\mathrm{G}}{ }^{2} & =3\left[\lambda_{0} /(4 \pi \mathrm{n})\right]^{2} \mathrm{C}_{01} / \mathrm{C}_{00} \\
\mathrm{~A}_{2} & =1 / 2 \mathrm{~K}^{\prime} \mathrm{C}_{10} \\
\mathrm{~A}_{3} & =1 / 3 \mathrm{~K}^{\prime} \mathrm{C}_{20} \\
\mathrm{~K}^{\prime} & =4 \pi^{2} \mathrm{n}_{\mathrm{B}}{ }^{2}(\mathrm{dn} / \mathrm{dc})^{2} /\left(\lambda_{0}{ }^{4} \mathrm{~N}_{\mathrm{A}} \mathrm{V}_{\mathrm{v}}{ }^{\mathrm{B}}\right)
\end{aligned}
$$

where:

$\lambda_{0}$ is the wavelength in vacuum of the scattered light, $632.8 \mathrm{~nm}$ in this work, $n$ and $n_{B}$ are the indices of refraction of the solvent and benzene taken as 1.326 and 1.496 , respectively calculated as described in 5.1.3, $\mathrm{dn} / \mathrm{dc}$ is the differential refractive index of the solution, measured as described in 5.1.2, $\mathrm{N}_{\mathrm{A}}$ is Avogadro's number, taken as $6.022 \times 10^{23} \mathrm{~mol}^{-1}, \mathrm{~V}_{\mathrm{v}}^{\mathrm{B}}$ is the Rayleigh ratio for the vertically polarized scattering of vertically polarized light from benzene, used for calibration and obtained as described in the following paragraph.

The "vertical-vertical" Rayleigh ratio $\mathrm{V}_{\mathrm{v}}$ is related to the Rayleigh ratio $R_{v}$ for the unpolarized scattering of vertically polarized He-Ne laser and the depolarization ratio $\rho_{\mathrm{v}}$ for polarized light by:

$$
\mathrm{V}_{\mathrm{v}}{ }^{\mathrm{B}}=\mathrm{R}_{\mathrm{v}}^{\mathrm{B}} /\left(1+\rho_{\mathrm{v}}\right)
$$

Using the published [10] values for benzene

$$
R_{v}^{B}=12.6_{3} \times 10^{-6} \mathrm{~cm}^{-1}
$$



$\rho_{\mathrm{v}}=0.265$, we obtain

$$
V_{v}{ }^{B}=9.98 \times 10^{-6} \mathrm{~cm}^{-1}
$$

\subsection{Results for SRM 1923}

Four independent sets of light scattering runs were made on SRM 1923 using methanol as solvent. Each set consisted of six independently made up solutions. The polymer for each solution within each set was taken from a different sample vial. Intensities were measured at ten scattering angles in the range from 37.5 to 142.5 degrees. The scattered intensities in each set were fitted by least squares to eqn (2), and the results were used to calculate $M_{w}, A_{2}$ and $A_{3}$ using eqns (3)-(7). No reliable estimate could be made of $R_{G}{ }^{2}$ at these low molecular weights. However, as discussed in section 5.5.11, slopes of the angular variation were not zero. The values of $\mathrm{M}_{w}, A_{2}$, and $A_{3}$ obtained from the four sets were then averaged. The resulting mean values and sample standard deviations are given in table 6. Light scattering gave a weight average molecular weight of about $26.9 \times 10^{3} \mathrm{~g}$ mole $e^{-1}$ with a sample standard deviation of $0.87 \times 10^{3} \mathrm{~g} \mathrm{~mole}^{-1}$ and a value of $\mathrm{A}_{2}$ of $0.0034 \mathrm{~mole} \mathrm{~cm}^{3} / \mathrm{g}^{2}$ with a standard deviation of 0.0012 mole $\mathrm{cm}^{3} / \mathrm{g}^{2}$.

The standard deviation of the mean for the average $\mathrm{M}_{\mathrm{w}}$ is $0.44 \times 10^{3} \mathrm{~g}$ mole $e^{-1}$. In compliance with the NIST policy [17] on reporting uncertainties in measurement, the component uncertainty due to variance among the four $\mathrm{M}_{\mathrm{w}}$ determinations is computed as the standard deviation of the mean and is listed in Table 8 .

\subsection{Results for SRM 1924}

Four independent sets of light scattering runs were made on SRM 1924 using methanol as solvent. Each set consisted of six independently made up solutions. The polymer for each solution within each set was taken from a different sample vial. Intensities were measured at ten scattering angles in the range from 37.5 to 142.5 degrees. The scattered intensities in each set were fitted by least squares to eqn (2), and the results were used to calculate $M_{w}, A_{2}$ and $A_{3}$ using eqns (3)-(7). Estimates could be made of $R_{\mathrm{G}}{ }^{2}$ at these molecular weights. However as discussed in the section 5.5.11 the slopes of the angular variation were not considered reliable. The meaning of this will be discussed section 5.5 .11$. The values of $\mathrm{M}_{w}, A_{2}$, and $A_{3}$ obtained from the four sets were then averaged. The resulting mean values and sample standard deviations are given in table 7. Light scattering gave a weight average molecular weight of about $120.9 \times 10^{3} \mathrm{~g}$ mole ${ }^{-1}$ with a sample standard deviation of $1.0 \times 10^{3}$ $g \mathrm{~mole}^{-1}$ and a value of $\mathrm{A}_{2}$ of $0.00089 \mathrm{~mole} \mathrm{~cm}^{3} / \mathrm{g}^{2}$.

The standard deviation of the mean for the average $\mathrm{M}_{\mathrm{w}}$ is $0.5 \times 10^{3} \mathrm{~g}$ mole $e^{-1}$. The component uncertainty due to variance among the four $\mathrm{M}_{w}$ determinations is calculated by the same process used to compute the 
corresponding component uncertainty in the $\mathrm{M}_{w}$ of SRM 1923 in section 5.3, and is listed in Table 9.

\subsection{Estimation of Systematic Uncertainties}

We list the likeliest sources of systematic uncertainty in the determination of weight-average molecular weight by light scattering described in the preceding sections, and attempt to estimate upper limits for their magnitudes. For this purpose, we employ a scheme similar to that used in Ref. [12] for the estimation of systematic uncertainties in SRM's 1482, 1483 and 1484. This scheme has been modified here to conform to NIST uncertainty reporting guideline in reference [17]. Following reference [17], Type A standard uncertainties are reported as the standard deviation of the mean of the measurement.

The limits of Type B uncertainties are assigned with such width that the probability of the measurement occurring outside these boundaries is extremely small. With the limits thus chosen, the resulting Type B uncertainties are estimated with at least a 95 percent level of confidence. Following the modelling guidance for Type B evaluation of standard uncertainty in reference [17], Type B standard uncertainties, $u_{i}$, are obtained by assuming a normal distribution between such assigned boundaries of at least 95 percent confidence interval estimates, and dividing the interval by a factor of 2 .

An effort is made to evaluate the effect of the standard uncertainty of each measurement in terms of uncertainty in the determined average value of the molecular weight. The result is equivalent to multiplying the standard uncertainty of the measurement by its corresponding sensitivity coefficient, $c_{i}$, as described in reference [17], to obtain a product, $c_{i} u_{i}$, in dimensions of percent of $\mathrm{M}_{w}$. The resulting factor, $c_{i} u_{i}$, is applied to the determined average $\mathrm{M}_{\mathrm{w}}$ value to obtain the standard uncertainty in

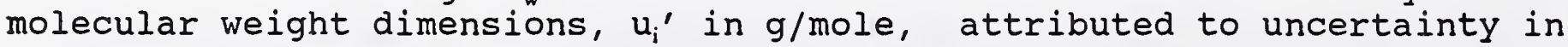
the component measurement:

$$
u_{i}^{\prime}=c_{i} u_{i} M_{w}
$$

These uncertainties are listed in table 8 and table 9 for SRM 1923 and SRM 1924 respectively.

\subsubsection{Indices of Refraction}

As in Ref. [12], we estimate that $0.1 \%$ is a proper upper limit for systematic uncertainties in $\mathrm{M}_{w}$ arising from uncertainties in the literature values of solvent index of refraction. Since this is at least a 95 percent confidence interval estimate, it provides a standard uncertainty of $0.05 \%$ in $\mathrm{M}_{\mathrm{w}}$.

5.5.2. Literature Value of $\mathrm{dn} / \mathrm{dc}$ for Aqueous $\mathrm{NaCl}$ and Calibration of the Differential Refractometer 
Calibration of the differential refractometer required interpolation of the data of Ref. [7] to the $633 \mathrm{~nm}$ wavelength used for the lightscattering measurements. We estimate the uncertainty in the interpolated values of $\Delta n$ as $0.6 \%$, due primarily to uncertainties in the interpolation process. As explained in 5.1.2, the dn/dc of PEO in methanol was computed from the combined results from two experimental determinations, and the differential refractometer had a different calibration for each of the two determinations. The first calibration factor determined for our differential refractometer had a relative standard deviation (rsd) of $0.038 \%$. Applying a coverage factor of 2 to this rsd yields a Type A expanded uncertainty of $0.076 \%$ for this measurement [17]. Combining this uncertainty with an allowance for possible linearity uncertainties in the refractometer, we estimate that a proper upper limit for uncertainty in $\mathrm{dn} / \mathrm{dc}$ is $1 \%$. Considered as a 95 percent confidence interval estimate, this quoted uncertainty provides a standard uncertainty of $0.5 \%$ which would contribute a $1 \%$ standard uncertainty in $\mathrm{M}_{\mathrm{w}}$ determination.

The second calibration factor for the differential refractometer had a relative standard uncertainty of $0.097 \%$. Applying a coverage factor of 2 to this calibration standard uncertainty yields an expanded uncertainty of $0.19 \%$ in the determined $\mathrm{dn} / \mathrm{dc}$. Combination of this uncertainty with other uncertainty estimates, as described in the preceding paragraph, also yields the same upper limit estimate for uncertainty in the measurement. Converted to a standard uncertainty of $0.5 \%$ in the determined $\mathrm{dn} / \mathrm{dc}$, this uncertainty, as in the first calibration, gives rise to a standard uncertainty of $1 \%$ in the $\mathrm{M}_{\mathrm{w}}$ determination. Consequently, an estimated standard uncertainty of $1 \%$ in the $M_{w}$ is attributed to uncertainty in the calibration of the differential refractometer.

\subsubsection{Measured Value of $\mathrm{dn} / \mathrm{dc}$ of SRM 1923 and SRM 1924}

The differential refractive index dn/dC of SRM 1923 and SRM 1924 in methanol at a temperature of $25{ }^{\circ} \mathrm{C}$. was determined as described in 5.1 .2 . The mean value obtained for $\mathrm{dn} / \mathrm{dc}$ was $0.1436 \mathrm{~cm}^{3} / \mathrm{g}$, with a standard deviation of $0.00029 \mathrm{~cm}^{3} / \mathrm{g}$ and 10 degrees of freedom. The relative standard deviation is then $0.00029 / 0.1436$, or $0.20 \%$, taken directly as the standard uncertainty. As the dn/dc appears raised to the second power in the $\mathrm{M}_{\mathrm{w}}$ calculation, the uncertainty in the calculated $\mathrm{M}_{\mathrm{w}}$ resulting from the uncertainty in the $\mathrm{dn} / \mathrm{dc}$ is estimated as twice the estimated uncertainty in the $\mathrm{dn} / \mathrm{dc}$, or $0.4 \%$.

\subsubsection{Wavelength of Radiation}

For the He-Ne laser employed in this work, uncertainties in the wavelength of the radiation are completely negligible compared with uncertainties from other sources.

\subsubsection{Rayleigh Ratio of Benzene}

For benzene at $632.8 \mathrm{~nm}$, Ref. [10] gives: $R_{\mathrm{V}, \mathrm{V}+\mathrm{H}}=12.6_{3} \times 10^{-6} \mathrm{~cm}^{-1}$ and $\rho_{\mathrm{v}}=0.265$, giving $R_{\mathrm{Vv}}=R_{\mathrm{V}, \mathrm{V}+\mathrm{H}} /\left(1+\rho_{\mathrm{v}}\right)=9.98 \times 10^{-6} \mathrm{~cm}^{-1}$. Abbreviate $R_{\mathrm{V}, \mathrm{V}+\mathrm{H}}$ 
and $\rho_{\mathrm{v}}$ by $R$ and $\rho$, respectively. The authors of Ref. [10] apparently believe that their R-values are accurate to $2 \%$ (systematic). They quote a relative standard deviation for their R-value for benzene of $0.21 / 12.63$, or $1.7 \%$. They do not give estimates of either accuracy or precision for their values of $\rho$. However, $\rho$ is obtained as the ratio of two intensities, the larger of which is, or is close to, the intensity measured for the determination of $R$. The photomultiplier detectors were apparently operated in the current mode, and it seems reasonable to suppose that the absolute uncertainty in the smaller intensity is the same as that of the larger, and that the relative uncertainty in the larger is the same as that in $R$. Then if $r$ is the rsd of $R$, we have for the standard deviation in $\rho: \operatorname{sd}(\rho)=\mathbb{V}\left(1+\rho^{2}\right)$ and $\operatorname{rsd}(1+\rho)=[r /(1+\rho)] V\left(1+\rho^{2}\right)$, and combining this with the rsd in $R$, we have $r s d\left(R_{\mathrm{vv}}\right)=[\mathrm{r} /(1+\rho)] \sqrt{2}\left(1+\rho+\rho^{2}\right)$, which is about 1 . $3 r$ for $\rho=$ 0.265 . The product, $1.3 \mathrm{r}=1.3 \times 1.7 \%$ yields a standard uncertainty $2.2 \%$. This standard uncertainty combined (by root-sum-squares) with the stated uncertainty of $2 \%$ for the R-values [10] yields a standard uncertainty of $3 \%$.

\subsubsection{Polarizer Uncertainties}

There are four of these: First, the "vertically polarized" laser beam actually contains "horizontally polarized" components for two reasons: First, the polarizer inside the laser head lets through a small fraction $\epsilon$ of the "wrong" polarization; Second, the principal axis of polarization of the light from the laser may not be exactly perpendicular to the plane of the incident and scattered beams. Both will cause light assumed to be vertically polarized to contain a small admixture of horizontally polarized light. The effect upon scattering signals from SRM 1923 and SRM 1924 will be slight, but the effect upon the benzene calibration signals is to change the effective Rayleigh ratio that should have been used from the $R_{V v}$ value toward the $R_{V, v+H}$ value. The resulting uncertainty in $M_{w}$ is $\rho \epsilon /(1-\epsilon)$ for the first effect and $\rho \tan ^{2} \alpha$, where $\alpha$ is the angular missetting, for the second. The uncertainty from both effects together is $\rho\left[\epsilon /(1-\epsilon)+\tan ^{2} \alpha\right]$.

Second, in an exactly analogous way, the analyzing polarizer in front of the detector may be nonideal and/or mispositioned. In this case, let $\delta$ be the contribution from the nonideality of the polarizer, and let $B$ be the angle of missetting. The resulting expression for the uncertainty is then: $\rho\left[\delta /(1-\delta)+\tan ^{2} \beta\right]$.

Finally, since all these uncertainties are of the same sign, we add them to get: $\rho\left[\epsilon /(1-\epsilon)+\tan ^{2} \alpha+\delta /(1-\delta)+\tan ^{2} \beta\right]$. Take $\epsilon=\delta=1 / 500$, $\alpha=5^{\circ}$, and $\beta=3^{\circ}$, and $\rho=0.265$. Then the uncertainty is $0.265[.0020+$ $.0077+.0020+.0027]=0.0038=0.4 \%$ with at least a $95 \%$ level of confidence considering the liberal boundaries assigned to the constituent uncertainties and their combination by linear summation instead of rootsum-of-squares. This quoted uncertainty provides an estimated standard uncertainty of $0.2 \%$. 


\subsubsection{Ratio of Working standard Scattering to Sample Scattering}

Since photon counting techniques were employed, there should be no systematic uncertainties from this source. Random uncertainties are reflected in the overall random uncertainty of the molecular weight.

\subsubsection{Solvent Density}

For the density of methanol at $25^{\circ} \mathrm{C}$, we used the value $0.78664 \mathrm{~g} / \mathrm{mL}$ as given in reference [5]. We estimate that this value is accurate to $0.1 \%$, or better. The resulting standard uncertainty on $\mathrm{M}_{w}$ is just $0.05 \%$.

\subsubsection{Solute Weights}

For the runs actually used in the final determination of $M_{w}$ for SRM 1923 and SRM 1924, the concentrations employed were nominal 0.2 to $1.6 \mathrm{~g} / \mathrm{L}$ for SRM 1923, and 0.1 to $1.2 \mathrm{~g} / \mathrm{L}$ for SRM 1924 , respectively. Solvent weights were chosen so that the solute weights were always about $0.05 \mathrm{~g}$. Using the uncertainty limit of $0.1 \mathrm{mg}$ we usually assign to the balance used to weigh the PEO samples, we have uncertainties in the solute weights of $0.2 \%$ (and comparatively negligible uncertainties in solvent weights). The uncertainty in $\mathrm{M}_{w}$ is then the uncertainty in solute weights, or about $0.2 \%$ with at least a 95 percent level of confidence. This 95 percent confidence interval estimate provides a standard uncertainty of $0.1 \%$.

\subsubsection{Reflection correction}

The refractive index of methanol at $23^{\circ} \mathrm{C}$ and $632.8 \mathrm{~nm}$ wavelength is given [10] as 1.327. The refractive index of the sample cell is given by the vendor as 1.474 at the $589 \mathrm{~nm}$ wavelength. Although the temperature of the methanol, and the wavelength for the refractive index of the cell, in this case are not correct for our experiments, these values should be adequate to estimate what will turn out to be an extremely small uncertainty. Substitution of these two refractive indices into Fresnel's equation for reflection from an interface between two transparent dielectrics [15] yields a reflectance factor $f=0.0028$. Comparison calculations of $M_{w}$ for both SRM 1923 and SRM 1924 show the resulting uncertainty to be less than $0.03 \%$, or for our purpose $0.0 \%$.

\subsubsection{Instrumental Misalignment}

In section 5.1.4 we discussed problems with instrument alignment in this system. For the geometry of the Brookhaven light scattering instrument, it is expected that any deviation from constancy of $I$ in $(\theta)$ is indicative of instrument misalignment. We find both symmetric and asymmetric contributions to the deviation from I $\sin (\theta)$ constancy. A typical plot of I $\sin (\theta) / I \sin (90)$ for one of the runs is seen in figure 5. The deviation is about $2 \%$ at each wing. We first consider the symmetric contribution to this deviation. Due to problems of refractive index difference between the cell ( $\mathrm{n}$ of glass is about 1.47) and the solvent ( $n$ of methanol is about 1.33), we expect a reflection correction 
associated with our scattering. This problem is worst at wide and narrow angles, and is exacerbated by the low intrinsic scattering of the solvent itself. This can be corrected for and generally is found to be small. It has been discussed in section 5.5 .10 .

Another symmetric contribution is caused by the flare at the interface between the cell and its methanolic contents where the laser beam enters and exits the sample. Like the reflection problem, the stray scattering arising from the flare is made worse as a result of the low scattering of the methanol.

Since all the symmetric effects are smaller at angles near 90 degrees, we estimate the uncertainty from these contributions by reanalyzing the data and obtained the molecular weight, and $A_{2}$ and $A_{3}$, by reducing the angle range fit for SRM 1923 and SRM 1924 from 45 to 135 degrees, and from 60 to 120 degrees.

For SRM 1923 this change in range of angle for the fit from 45 to 135 degrees changed the molecular weights from the four sets of data by $1.3 \%$, $0.9 \%,-0.5 \%$ and $1.5 \%$. Fitting over the reduced angular range of 60 to 120 degrees changed the molecular weight values from the four sets of data by $0.7 \%,-1.5 \%,-1.9 \%$ and $-0.7 \%$. Thus for SRM 1923 we estimate the uncertainty from this cause to be about $1.5 \%$ with a 95 percent level of confidence. This 95 percent confidence interval estimate provides an estimated standard uncertainty of $0.8 \%$.

For SRM 1924 this change in range of angle for the fit from 45 to 135 degrees changed the molecular weights from the four sets of data by $0.9 \%$, $0.7 \%, 0.01 \%$ and $0.3 \%$. Fitting over the reduced angular range of 60 to 120 degrees changed the molecular weight values from the four sets of data by $0.5 \%, 0.5 \%,-0.9 \%$ and $-0.7 \%$. Thus for SRM 1924 we estimate the uncertainty from this cause to be about $0.8 \%$, with a 95 percent level of confidence. This 95 percent confidence interval estimate provides an estimated standard uncertainty of $0.4 \%$.

Superimposed on this large symmetric term around 90 degrees there appears to be an asymmetric deviation which appears to give more scattering at wider angles than at small. This asymmetric effect manifests itself as a slightly negative slope in the $\sin ^{2}(\theta / 2)$ plot on the Zimm plot for the lowest molecular weight SRM, SRM 1923. This deviation most likely arises from a small displacement of the cylindrical axis of the cell from the optical or mechanical axis of the goniometer.

The displacement of the cylindrical axis of the cell from the optical axis of the goniometer is attributed to eccentricity of the cell geometry from that of an ideal cylinder, the eccentricity varying among the cells. The eccentricity was observed indirectly by prominent reflections of the laser beam, from the incident and emergent interfaces between the inner cell wall and its methanolic contents, onto the mask on the emergent side of the beam focusing lens. As the cell was rotated about its cylindrical axis in the sample vat, the twin reflections would move through a 
continuous cycle of symmetrically spreading apart to a limiting distance of separation, then approach each other and superimpose at a crossing point nearly coincident with the emergent port for the laser beam through the mask. As rotation of the cell continued, the reflections would then spread apart in opposite directions to the limiting distance of separation, and reconverge to the same superposition at the crossing point again. The cyclic movement of the twin reflections appeared primarily horizontal, with a small vertical component indicating movement of the reflections also through a very small angle in a vertical plane. It was recognized that this eccentricity of the cell was also bending the laser beam at the incident glass-methanol interface through a very small angle of displacement from the original alignment as the beam passed through the methanolic contents of the cell. It was hypothesized that the light bending condition contributed to both the symmetric and asymmetric terms of deviation detected in the $\mathrm{zimm}$ and Isin $\theta$ plots. As routine practice during the characterization experiments, each solvent or solution cell was aligned in the sample vat by adjusting its rotational orientation in the laser beam in such a way that the indicative twin reflections superposed at the crossing point very near the emergent port for the laser beam through the focussing lens mask. This procedure was applied in quest of minimizing the beam bending and reflection problems. The problem was considered essentially nonexistent when the cell contains a sample very nearly isorefractive with the glass. For example, although the twin reflections from the standard benzene cell showed similar continuous movement through a cycle as described for a methanol cell, the reflections from the benzene cell were almost imperceptibly dim, and the form of the Isin $\theta$ plots of scattering from the benzene cell showed far less dependence on the rotational orientation of the cell than did the scattering from the methanol cell.

This asymmetric term seems to appear in the solvent data when we try to obtain a fit to I $\sin (\theta)$ for the alignment test. When we do such a fit of the solvent data to a simple cotangent function we find a deviation of about 0.4 degree. This is hardly a reliable number since it is difficult to separate the asymmetric and symmetric contributions to the $I$ sin $\theta$ in the alignment test fit. Thus all the data reported in table 6 and table 7 for the molecular weight certification was fit with the correction angle at 0.0 degrees. To see the effect of this asymmetric term on the molecular weight we then refit the data assuming correction angles of 0.5 degree and 1.0 degree.

For SRM 1923 a 0.5 degree correction was found to change the molecular weight by $1.3 \%, 1.3 \%, 1.2 \%$ and $1.3 \%$ for each of the sets respectively. A 1.0 degree correction was found to change the molecular weight by $2.6 \%$ for each of the sets. Since we expect the correction to be about 0.4 degrees, we estimate the contribution to the uncertainty from this effect on SRM 1923 as $1.3 \%$ with a 95 percent level of confidence. This 95 percent confidence interval estimate provides an estimated standard uncertainty of $0.7 \%$ for the determined $M_{w}$ of SRM 1923 .

For SRM 1924 a 0.5 degree correction was found to change the 
molecular weight by $1.1 \%, 1.3 \%, 1.3 \%$ and $1.4 \%$ for each of the sets respectively. A 1.0 degree correction was found to change the molecular weight by $2.5 \%, 2.6 \%, 2.5 \%$ and $2.7 \%$ for each of the sets, respectively. Since we expect the correction to be about 0.4 degrees, we estimate the contribution to the uncertainty from this effect on SRM 1924 as $1.4 \%$ with at least a 95 percent level of confidence. This 95 percent confidence interval estimate provides an estimated standard uncertainty of $0.7 \%$ on the determined $M_{w}$ of SRM 1924 .

We then estimate the uncertainty from both components described above to be the sum of the standard uncertainties. Thus expect a total standard uncertainty arising from instrument misalignment of $1.5 \%$ for SRM 1923 and $1.1 \%$ for SRM 1924 .

\subsubsection{Refraction Correction}

A detailed analysis of the optical geometry of the light scattering instrument employed in this work can not be carried out, since the main detector optics unit was inaccessible. However, rough analyses based on assumptions about the internal geometry of the detector unit lead to an uncertainty of about $0.3 \%$. A reasonable uncertainty limit might then be about twice this, or $0.6 \%$, from which we estimate a standard uncertainty of $0.3 \%$ on $\mathrm{M}_{w}$ due to refraction uncertainty.

\subsubsection{Anisotropy of Solute}

We know of no reported data on the optical anisotropy of poly (ethylene oxides) like SRM 1923 and SRM 1924 in solution. Since the light scattering experiments were conducted with vertically polarized incident light, and the measuring optics included a polarizer aligned to pass only vertically polarized light, we have determined the extent to which the light scattered by the polymer was also depolarized by the polymer. The depolarization ratio was determined by measuring the intensity of the light scattered at an angle of $90^{\circ}$ (I(90)) from the vertically polarized incident beam by a sample of SRM 1923 at a concentration of $2 \mathrm{~g} / \mathrm{L}$, higher than that used in any of the characterization runs. The $I(90)$ from both a solvent sample and a solution sample was measured with the detector polarizer aligned both in the vertical plane and in the horizontal plane for each sample.

From the above data, $\mathrm{H}_{\mathrm{v}} / \mathrm{V}_{\mathrm{v}} \equiv \rho_{\mathrm{v}}$ was then estimated as 0.000866 with a standard deviation of 0.000394 for SRM 1923 ; then $\mathrm{M}_{\mathrm{w}}$ (corrected) $=\mathrm{M}_{\mathrm{w}}$ (apparent) $\times\left[1-(4 / 3) \rho_{\mathrm{v}}\right]$. Then we estimate the relative uncertainty in $\mathrm{M}_{\mathrm{w}}$ due to the depolarization as:

$(4 / 3) * .000866=0.0011$. Considering the uncertainty in the measurement of depolarization we accept a contribution from this as an uncertainty of $0.2 \%$ with a $95 \%$ level of confidence. This 95 percent confidence interval estimate provides an estimated standard uncertainty of $0.1 \%$ in the determined $\mathrm{M}_{\mathrm{w}}$ of the polymer resulting from its anisotropy in solution. 


\subsubsection{Cutoff of Virial Expansion for SRM 1923}

As described in section 5.2., the solution concentrations used for the final analyses were limited to a region where linear terms in $c$ and $\mathrm{X} \equiv \sin ^{2}(\theta / 2)$ appeared to suffice. To check this further, we used our data to estimate values of $A_{2}$ and $A_{3}$. These are shown in table 6 . We should note in passing that zhou and Brown [16] report an $A_{2}$ of a 40,000 molecular weight poly (ethylene oxide) of $0.00295 \mathrm{~cm}^{3} \mathrm{~mol} / \mathrm{g}^{2}$ in methanol at $25{ }^{\circ} \mathrm{C}$, close to the value we report for SRM 1923 .

From the data in table 6 the average value of $A_{3}$ is much smaller than its standard deviation. This suggests that the contribution from the term in $A_{3}$ is not significant in this measurement. Furthermore, if $A_{3}$ were to contribute significantly to the extrapolation to zero concentration scattering to obtain the molecular weight, then $1.5 \mathrm{~A}_{3} \mathrm{c}_{\mathrm{m}}^{2}$, where $\mathrm{c}_{\mathrm{m}}$ is the maximum concentration used in the fitting scheme, would have a value on the order of $A_{2}$. If we use the average value of $A_{3}$ from table 5 , this product is two orders below $A_{2}$. If we use the maximum value of $A_{3}$ found in table 5 this product is less than the standard deviation in $A_{2}$. Thus we are confident that $A_{3}$ makes no significant contribution in this concentration range to the extrapolation of the light scattering results to zero concentration.

To estimate the uncertainty arising from $A_{3}$, comparison calculations of $\mathrm{M}_{\mathrm{w}}$ show that allowing terms in $\mathrm{c}^{2}, \mathrm{cX}$, and $\mathrm{X}^{2}$ in the analyses changes the calculated values of $\mathrm{M}_{w}$ from the four sets of data by $-2.0 \%, 3.0 \%$, $1.5 \%$, and $1.2 \%$, respectively. However, the second and fourth of these results are negative third viral coefficients, which we reject as unphysical. We therefore take the larger in magnitude of the remaining two, $2 \%$ as at least a 95 percent confidence interval estimate of uncertainty from this source. This quoted estimate provides an estimated standard uncertainty of $1 \%$ in the determined $\mathrm{M}_{w}$ of SRM 1923 due to truncation of the virial expansion.

\subsubsection{Cutoff of Virial Expansion for SRM 1924}

As described in section 5.2., the solution concentrations used for the final analyses for SRM 1924 were limited to a region where linear terms in $c$ and $x \equiv \sin ^{2}(\theta / 2)$ appeared to suffice. To check this further, we used our data to estimate values of $A_{2}$ and $A_{3}$. These are shown in table 7. From the data in table 7 the average value of $A_{2}$ is much smaller than it was for SRM 1923. Zhou and Brown [16] have seen that $A_{2}$ decreases with increasing molecular weight for polyethylene oxide in methanol. However our value of $\mathrm{A}_{2}$ is much smaller than theirs. We have no explanation at this point for this inconsistency.

With such a small $A_{2}$, the contribution from $A_{3}$ is more significant. still the standard deviation in $A_{3}$ is larger than its average value. If $A_{3}$ were to contribute significantly to the extrapolation to zero concentration scattering to obtain the molecular weight, then $1.5 \mathrm{~A}_{3} \mathrm{C}_{\mathrm{m}}^{2}$ where $c_{m}$ is the maximum concentration used in the fitting scheme, would 
have a value on the order of $A_{2}$. If we use the average value of $A_{3}$ from table 7 , this product is about one fifth of $A_{2}$. If we use the maximum value of $A_{3}$ found in table 7 this product is about one quarter of $A_{2}$. These arguments suggest $A_{3}$ is not significant in these concentration ranges.

To estimate the uncertainty arising from $A_{3}$, comparison calculations of $\mathrm{M}_{\mathrm{w}}$ show that allowing terms in $\mathrm{c}^{2}, \mathrm{cX}$, and $\mathrm{X}^{2}$ in the analyses changes the calculated values of $\mathrm{M}_{\mathrm{w}}$ from these four sets of data by $1.3 \%,-1.2 \%$, $2.7 \%$, and $-0.8 \%$, respectively. However, the first of these results is a negative third viral coefficient, which we reject as unphysical. We therefore take the larger in magnitude of the remaining three, $2.7 \%$, as at least a 95 percent confidence interval estimate of the uncertainty from this source. This 95 percent confidence interval estimate provides a standard uncertainty of $1.4 \%$ in the determined $\mathrm{M}_{w}$ of SRM 1924 resulting from truncation of the virial expansion.

\subsubsection{Solute Degradation}

By their nature light scattering experiments are of short duration. A number of solutions can be prepared and run by light scattering in a single day. To check for degradation during the running of an experiment, several solutions of SRM 1923 were made up and a light scattering experiment was run twice during the day. The samples were then stored in the dark and run three days later, six days later, seven days later and a ten days later. The apparent molecular weights of these solutions in these four determinations were found to change by $+1.1 \%,+2.2 \%,+0.3 \%$ and $+0.6 \%$ respectively. SRM 1923 is clearly not degrading in this period. In fact, the changes in the molecular weights found in this time sequence are about one standard deviation found in fitting the molecular weight data of any given run.

A similar series of experiments were run for SRM 1924. Several solutions of SRM 1924 were made up and a light scattering experiment was run twice during the day. The samples were then stored in the dark and run one day later, four days later, and a thirteen days later. The apparent molecular weights of these solutions in these four determinations were found to change by $+0.05 \%$, +0.8\% and $-0.8 \%$ respectively. SRM 1924 is clearly not degrading in this period. In fact, the changes in the molecular weights found in this time sequence are about one standard deviation of any given run.

As long as we prepare fresh solutions and run them within a day or two, we expect no problem. This was our practice during the entire series of light scattering experiments.

Time-dependence studies of apparent molecular weight, described above, showed little change in apparent molecular weight with time. From the fact that the changes in apparent $M_{w}$ of SRM 1923 were less than $1 \%$ in 72 hours, and the structure of the experiments, we conclude that a reasonable limit for uncertainty due to sample degradation is $0.5 \%$ for SRM 
1923. Likewise, a limit of the uncertainty arising for solution degradation for SRM 1924 is also 0.5\%. These are limits for at least a 95 percent confidence interval estimate of the uncertainty. This 95 percent confidence interval estimate provides a standard uncertainty of $0.3 \%$ in the determined $\mathrm{M}_{\mathrm{w}}$ of both poly (ethylene oxides) due to possible degradation of the polymer in solution.

\subsubsection{Summary}

The standard deviation of the mean of the determined molecular weight values, from analysis of variance of the experimental data, and the systematic uncertainties obtained from section 5.5.1 through 5.5.15 are listed in tables 8 and 9 for SRM 1923 and SRM 1924 respectively. As noted in section 5.5, the values of systematic uncertainties iterated in section 5.5.1 through 5.5.15 are equivalent to the products of sensitivity coefficients, $c_{i} \equiv\left(\partial f / \partial x_{i}\right)$, and their corresponding systematic standard uncertainties, $u_{i}$, in dimensions of percent of $\mathrm{M}_{w}$. Thus the systematic standard uncertainties are listed initially as $c_{i} u_{i}$ in dimensions of $\% M_{w}$ in the tables, and then translated to dimensions of $M_{w}, u_{i}^{\prime}$, in the adjacent columns. The tables of components of uncertainty in the certificates for SRM 1923 and SRM 1924 are abstracted from tables 8 and 9 respectively in this report.

The combined standard uncertainties, $u_{c}$, of SRM 1923 and SRM 1924 respectively are computed as root-sum-of-squares of the component standard uncertainties, $u_{i}{ }^{\prime}$, following the recently formalized NIST policy for evaluating and expressing uncertainty in measurements [17]. We find that the combined standard uncertainty, $u_{c}$, of SRM 1923 is $1.09 \times 10^{3} \mathrm{~g} / \mathrm{mole}$, rounded to $1.1 \times 10^{3} \mathrm{~g} / \mathrm{mole}$, and that for SRM 1924 is $4.48 \times 10^{3} \mathrm{~g} / \mathrm{mole}$, rounded to $4.5 \times 10^{3} \mathrm{~g} / \mathrm{mole}$. The reader should note that both combined uncertainties are dominated by the estimated uncertainty in Raleigh ratio of the scattering standard.

\subsection{Conclusions}

The weight average molecular weight of SRM 1923, a poly(ethylene oxide), was determined to be $26.9 \times 10^{3} \mathrm{~g} \cdot \mathrm{mole} \mathrm{e}^{-1}$ by light scattering, with a combined standard uncertainty $u_{c}=1.1 \times 10^{3} \mathrm{~g} \cdot \mathrm{mole} \mathrm{e}^{-1}$, and a combined expanded uncertainty $U_{c}=2.2 \times 10^{3} \mathrm{~g} \cdot \mathrm{mole} \mathrm{e}^{-1}$.

The weight average molecular weight of SRM 1924 , a poly (ethylene oxide), was determined to be $120.9 \times 10^{3} \mathrm{~g} \cdot \mathrm{mole}-1$ by light scattering, with a combined standard uncertainty $u_{c}=4.5 \times 10^{3} \mathrm{~g} \cdot \mathrm{mol} \mathrm{e}^{-1}$, and a combined expanded uncertainty $U_{c}=9.0 \times 10^{3} \mathrm{gmole} \mathrm{m}^{-1}$. 


\section{Table 1}

Comparisons of Chromatograms from reinjections of same solution of SRM 1923

Bottle bulk

SEC Run \#

6354

6355

6356

6357
Match Factor

998.92
998.98
998.69

Comparison of Chromatograms from different solutions made up from a single vial of SRM 1923

Vial \#72

SEC Run \#

6351

6360

6369

Vial 101

SEC Run \#

635

6361

6371

Vial 257

SEC Run \#

6350

6366

6368

Vial 188

SEC Run \#

6352

6364

6370

\author{
Match Factor \\ $\overline{999.6}$ \\ 999.4
}

Match Factor

999.7

999.2

Match Factor

$\overline{999.1}$

999.3

Match Factor

997.7

999.1 
Table 2

Match factor of chromatograms from solutions freshly made up of SRM 1923. All are compared to a chromatogram run number 6354 from the bulk sample.

SEC Run \#

6354

6358

6359

6360

6361

6362

6363

6364

6365

6366

6367
Vial \#

bulk

1

40

72

101

124

157

188

218

257

last
Match Factor

$\overline{999.03}$

998.87

998.78

999.12

998.03

998.08

994.57

996.10

998.29

998.07 


\section{Table 3}

Comparison of Chromatograms from solutions made up from a single vial of SRM 1924

Vial 5

SEC Run \#

7167

7168

7172

7184

7162

Vial 55

SEC Run \#

7169

7170

7171

7178

Vial 294

SEC Run \#

7149

7152

7166

7164
Match Factor

$$
\begin{aligned}
& \overline{999.7} \\
& 998.1 \\
& 998.0 \\
& 999.8
\end{aligned}
$$

Match Factor

$\overline{999.7}$

995.2

998.4

Match Factor

$\overline{999.8}$

990.7

991.7 


\section{Table 4}

Match factor of chromatograms from solutions freshly made up of SRM 1924. All are compared to a chromatogram for vial \# 73 .

$\begin{array}{lll}\text { SEC Run \# } & \text { Vial \# } & \text { Match Factor } \\ 7157 & 73 & \\ 7147 & 1 & 999.5 \\ 7148 & 122 & 999.7 \\ 7149 & 294 & 999.7 \\ 7150 & 86 & 999.3 \\ 7151 & 181 & 999.8 \\ 7153 & 216 & 999.7 \\ 7154 & 207 & 999.8 \\ 7155 & 244 & 999.8 \\ 7156 & 283 & 998.7 \\ 7158 & 68 & 999.8 \\ 7159 & 157 & 999.8 \\ 7161 & 293 & 995.2 \\ 7162 & 5 & 994.4 \\ 7163 & 253 & 993.8 \\ 7165 & 90 & 993.6 \\ 7170 & 55 & 998.3 \\ 7179 & 324 & 997.5 \\ 7180 & 371 & 997.5 \\ 7181 & 362 & 997.5 \\ 7182 & 295 & 997.1 \\ 7183 & 354 & 998.1 \\ 7185 & 403 & 995.6\end{array}$




\section{Table 5 \\ Refractive Increment/Concentration Ratios for SRM 1923 and SRM 1924 Solutions of corresponding concentrations}

PEO

SRM 1923

SRM 1924

SRM 1923

SRM 1924

SRM 1923

SRM 1924
CONC. $\mathrm{mg} \mathrm{Cm}^{-3}$

$2.001_{8}$

1.9999

$3.001_{6}$

$3.000_{1}$

$5.005_{2}$

$5.002_{3}$
$\Delta \mathrm{n} \times 10^{4}$

$2.9039_{36}$

$2.8906_{21}$

$4.3365_{98}$

$4.3126_{31}$

$7.1899_{38}$

$7.1859_{44}$
$\Delta \mathrm{n} / \mathrm{c} \mathrm{cm}^{3} \mathrm{q}^{-1}$

$0.1450_{66}$

$0.1445_{38}$

$0.1444_{76}$

$0.1437_{50}$

$0.1436_{49}$

$0.1436_{53}$ 
Table 6

Molecular Weight, $A_{2}$ and $A_{3}$ for SRM 1923

\begin{tabular}{|c|c|c|c|}
\hline $\begin{array}{l}\text { Run } \\
\text { Label }\end{array}$ & $\begin{array}{l}\mathrm{M}_{\mathrm{W}} \times 10^{-3} \\
\mathrm{~g} / \mathrm{mol}\end{array}$ & $\stackrel{\mathrm{A}_{2}}{\mathrm{~cm}^{3} \mathrm{~mol} / \mathrm{g}^{2}}$ & $\stackrel{\mathrm{A}_{3}}{\mathrm{~cm}^{6} \mathrm{~mol} / \mathrm{g}^{3}}$ \\
\hline $\begin{array}{l}\text { L921030a } \\
\text { L921106a } \\
\text { L921116a } \\
\text { L921124a }\end{array}$ & $\begin{array}{l}25.7 \\
27.4 \\
26.9 \\
27.6\end{array}$ & $\begin{array}{l}0.00245 \\
0.00378 \\
0.0025 \\
0.00473\end{array}$ & $\begin{array}{r}0.22 \\
-0.29 \\
0.32 \\
-0.57\end{array}$ \\
\hline $\begin{array}{l}\text { Average } \\
\text { Sample } \\
\text { Standard } \\
\text { Deviation }\end{array}$ & 26.9 & 0.00342 & -0.08 \\
\hline $\begin{array}{l}\text { Standard } \\
\text { Deviation } \\
\text { of Mean }\end{array}$ & 0.44 & & \\
\hline
\end{tabular}




\section{Table 7}

Molecular Weight, $A_{2}$ and $A_{3}$ for SRM 1924

$\begin{array}{lccc}\begin{array}{l}\text { Run } \\ \text { Label }\end{array} & \begin{array}{c}\mathrm{M}_{\mathrm{W}} \times 10^{-3} \\ \mathrm{~g} / \mathrm{mol}\end{array} & \begin{array}{c}\mathrm{A}_{2} \\ \mathrm{Cm}^{3} \mathrm{~mol} / \mathrm{g}^{2}\end{array} & \begin{array}{c}\mathrm{A}_{3} \\ \mathrm{~cm}^{6} \mathrm{~mol}^{1} / \mathrm{g}^{3}\end{array} \\ \text { L921208a } & 121.9 & 0.00108 & -0.10 \\ \text { L921106a } & 120.0 & 0.00085 & 0.12 \\ \text { L921222a } & 119.9 & 0.00077 & 0.18 \\ \text { L921230a } & 121.6 & 0.00087 & 0.11 \\ & & & \\ \text { Average } & 120.9 & 0.00089 & 0.078 \\ \text { Sample } & & & \\ \text { Standard } & & & \\ \text { Deviation } & 1.0 & 0.00013 & \\ \quad & & \\ \text { Standard } & & & \\ \begin{array}{l}\text { Deviation } \\ \text { of Mean }\end{array} & 0.5 & & \end{array}$


Components of Uncertainty, and Combined Uncertainty Weight-Average Molecular Weight of SRM 1923

Source of uncertainty

Standard deviation of the mean $\mathrm{M}_{\mathrm{w}}{ }^{\mathrm{d}}$

Solvent index of refraction

Calibration of differential refractometer

Differential refractive index

Wavelength of light

Rayleigh ratio of scattering standard

Light polarizers

Ratio of standard scattering to sample scattering

Solvent density

Solute weights and solvent weights

Light reflection

optical alignment

Refraction correction

Anisotropy of polymer in solution

Truncation of virial expansion

Solute degradation

\begin{tabular}{|c|c|c|c|}
\hline & $c_{i} u_{i}^{b}$ & $\stackrel{\mathrm{u}_{\mathrm{i}}^{\prime}}{\mathrm{g} / \mathrm{mol}}$ & \\
\hline$\nu_{\mathrm{i}}^{\mathrm{a}}$ & $\%$ of $M_{w}$ & $\times 10^{3}$ & Type \\
\hline 3 & & 0.44 & A \\
\hline & 0.05 & 0.01 & B \\
\hline 5 & 1.0 & 0.27 & A \\
\hline 10 & 0.4 & 0.11 & A \\
\hline & $\mathrm{NS}^{\mathrm{e}}$ & $\prec 0.01$ & B \\
\hline & 3.0 & 0.81 & B \\
\hline & 0.2 & 0.05 & B \\
\hline & NS & $\prec 0.01$ & B \\
\hline & 0.05 & 0.01 & B \\
\hline & 0.1 & 0.03 & B \\
\hline & NS & $\prec 0.01$ & B \\
\hline & 1.5 & 0.40 & B \\
\hline & 0.3 & 0.08 & B \\
\hline & 0.1 & 0.03 & B \\
\hline & 1.0 & 0.27 & B \\
\hline & 0.3 & 0.08 & B \\
\hline
\end{tabular}

Combined standard uncertainty: $u_{c}=1.0, \times 10^{3} \mathrm{~g} / \mathrm{mole}$ by root-sum-of-squares of $u_{i}^{\prime}[17]$.

a. $\quad \nu_{\mathrm{i}}=$ Degrees of freedom.

b. $\quad c_{i} \equiv\left(\partial f / \partial x_{i}\right)$, sensitivity coefficient.

c. Type of uncertainty [17]:

Type A uncertainties are evaluated by statistical methods.

Type $B$ uncertainties are evaluated by other means.

d. The standard uncertainty, $u_{i}$, is equated with the standard deviation of the mean when computed from analysis of variance of a statistical population of measurements [17].

e. $\quad$ NS = "not significant:" the uncertainty is too small in comparison with others in the population to have a significant effect in the computed combined uncertainty. 
Table 9

Components of Uncertainty, and Combined Uncertainty Weight-Average Molecular Weight of SRM 1924

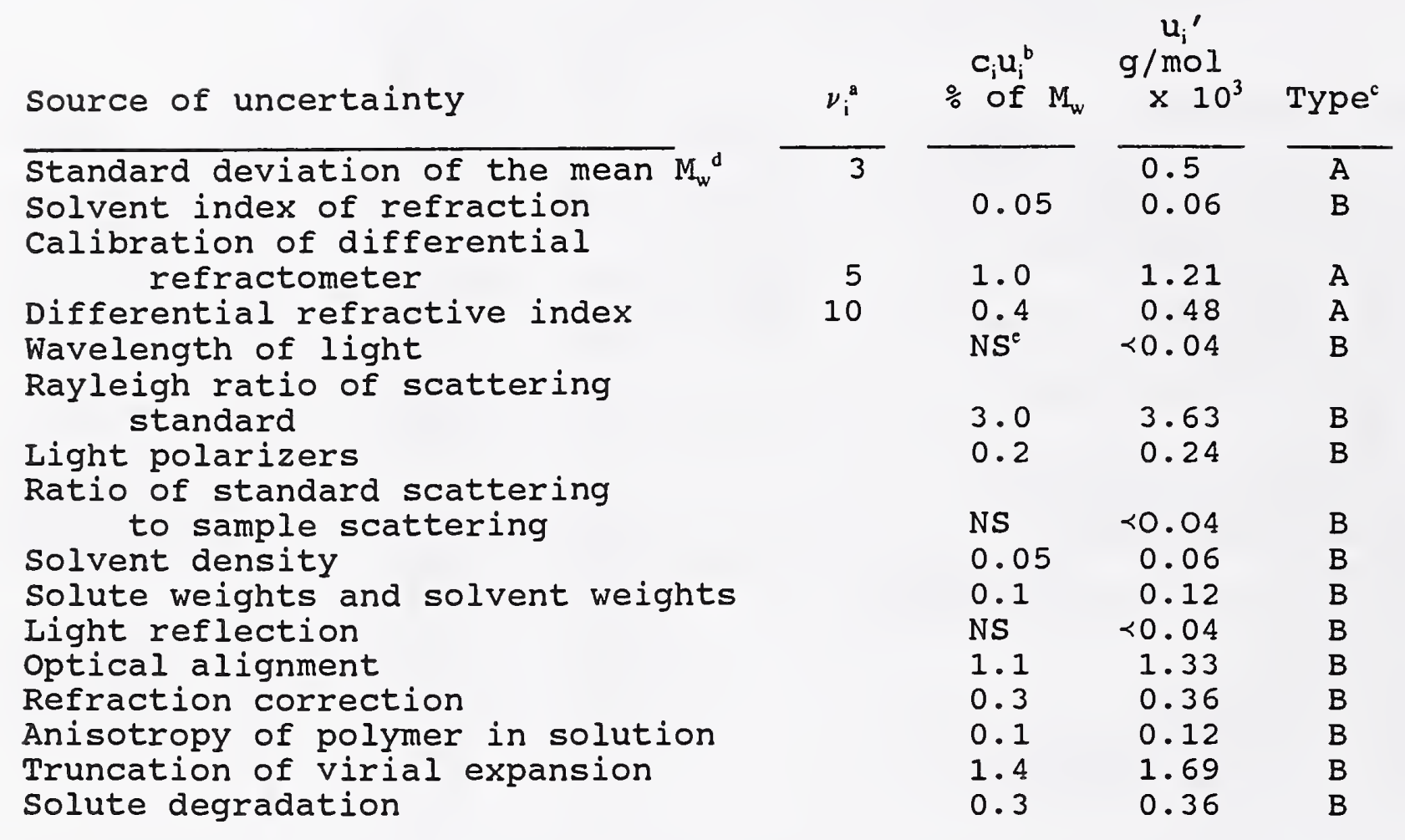

Combined standard uncertainty: $u_{c}=4.4_{8} \times 10^{3} \mathrm{~g} / \mathrm{mole}$ by root-sum-of-squares of $u_{i}^{\prime}[17]$.

a. $\quad \nu_{i}=$ Degrees of freedom.

b. $\quad c_{i} \equiv\left(\partial f / \partial x_{i}\right)$, sensitivity coefficient.

c. Type of uncertainty [17]:

Type A uncertainties are evaluated by statistical methods.

Type $B$ uncertainties are evaluated by other means.

d. The standard uncertainty, $u_{i}$, is equated with the standard deviation of the mean when computed from analysis of variance of a statistical population of measurements [17].

e. NS = "not significant:" the uncertainty is too small in comparison with others in the population to have a significant effect in the computed combined uncertainty. 
References

[1] See for example Howard W. Alexander "Elements of Mathematical Statistics", John Wiley \& Sons, 1961 , pg. 165-170 or K. A. Brownlee "Statistical Theory and Methodology in Science and Engineering," John Wiley \& Sons, Inc., 1960, pg. 56.

[2] For a discussion of match factors see Barry J. Bauer, Brian Dickens and William Blair, "Chromatographic Examination of Intaglio Inks, Resins and Varnishes", NISTIR 4949, 1991, and L. Huber, "Application of the Diode-Array Detector in HPLC", Hewlett Packard, France, 08/89, pg. 89100 .

[3] C. W. McGary, Jr, "Degradation of Poly (ethylene oxide)" J. of Polym. Sci., 46, 51-57 (1960).

[4] H.-G. Elias, Makromol. Chem., 50, 1-19 (1961).

[5] J. A. Riddick and W. B. Bunger, "Organic Solvents, Phys. Properties and Methods of Purification," Wiley-Interscience, New York, 1970, Table 58, pg 145 .

[6] ibid., Table 30, pg 107.

[7] A. Kruis, Z. Physik. Chem. B 34, 13-50 (1936).

[8] R. J. Anderson, Appl. Opt. 8, 1508-1509 (1969).

[9] LDC Analytical, "Instruction Manual for KMX-16 Laser Differential Refractometer" Section 5.3, "Calculation of Calibration Constant," Riviera Beach, FL, USA.

[10] W. Kaye and J. B. McDaniel, Appl. Opt., 13, 1934-1937 (1974).

[11] B. L. Johnson and J. Smith, "Refractive Indices and Densities of Some Common Polymer Solvents," Chapt. 2 in "Light Scattering from Polymer Solutions," Ed M. B. Huglin, Academic Press, London and N.Y., (1972).

[12] Charles C. Han, Herman L. Wagner, and Peter H. Verdier, "The Characterization of Linear Polyethylene SRM's 1482, 1483, and 1484 III Weight-Average Molecular Weights by Light Scattering." NBS Special Publication 260-61, P.H. Verdier and H.L. Wagner ed. December 1978 or National Bureau of Standards, Journal of Research, Vol. 83, No. 2, March - April, 1978, pg. 185-193.

[13] M. Kerker, "The Scattering of Light," Academic Press, N.Y., (1969). 
[14] H. Yamakawa, "Modern Theory of Polymer Solutions," Harper \& Row, N.Y., (1971).

[15] H. Utiyama, "Calibration and Correction Factors," Chapt. 4 in "Light scattering from Polymer Solutions," Ed M. B. Huglin. pp 61-88, Academic Press, N.Y., (1972).

[16] P. Zhou and W. Brown, Macromol. 23 1131-1139 (1990).

[17] B. N. Taylor and C. E. Kuyatt, "Guidelines for Evaluating and Expressing the Uncertainty of NIST Measurement Results." NIST Technical Note 1297, January 1993.

[18] C. Strazielle, "Etude par diffusion de la lumiere des heterogenéites rencontrees dans les solutions de Polyoxyethylene," Makromol. Chem. 119 50-63 (1968). 


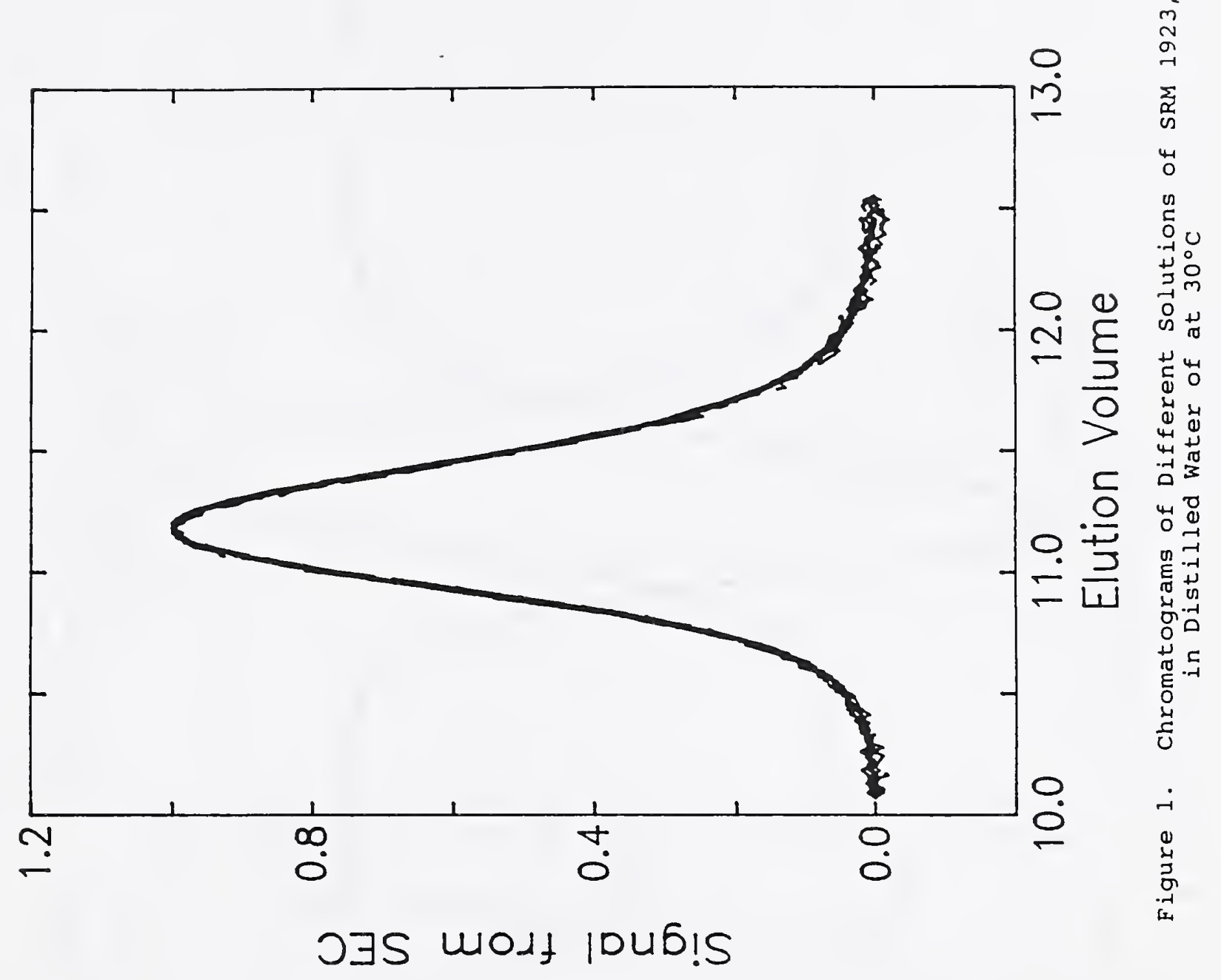




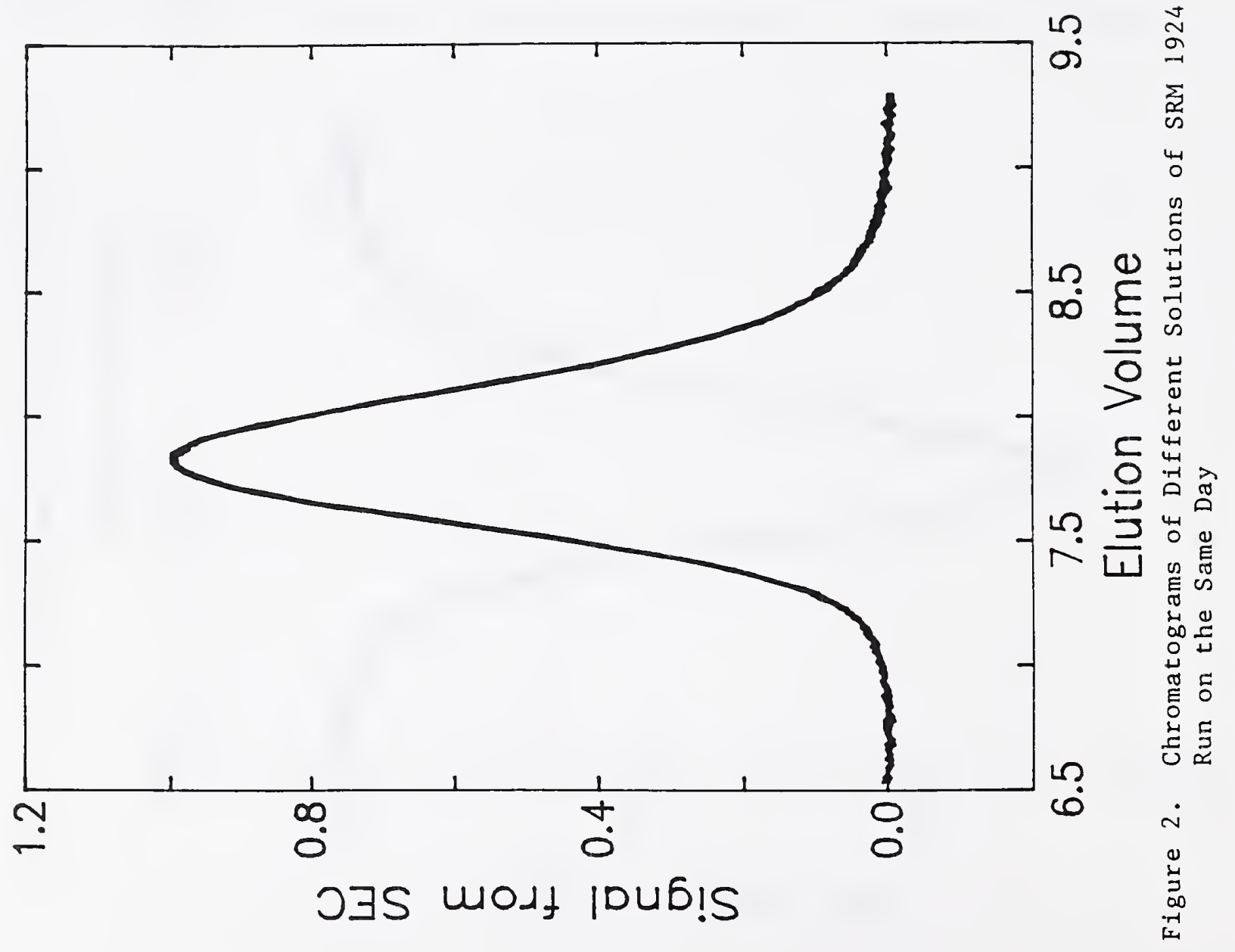




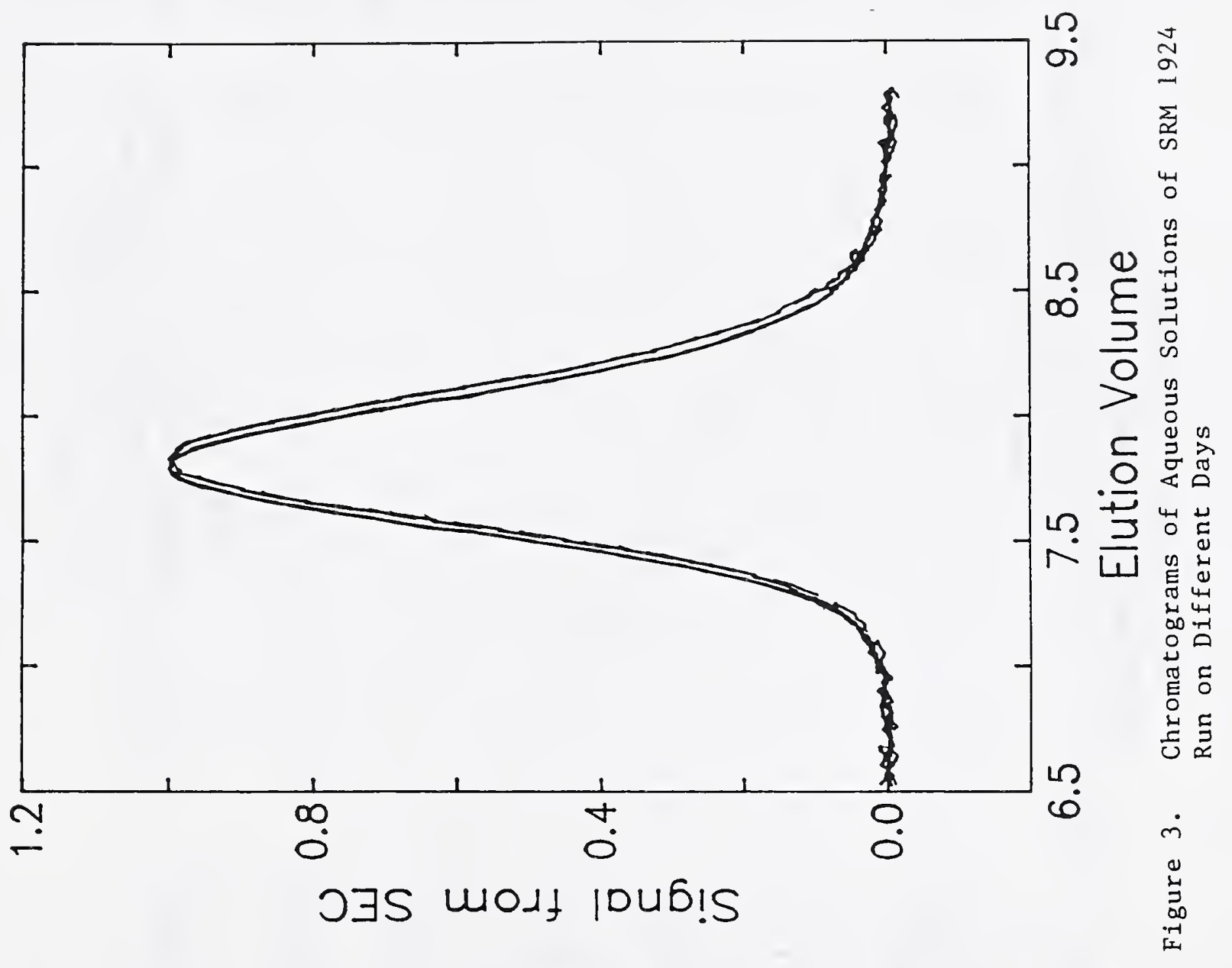




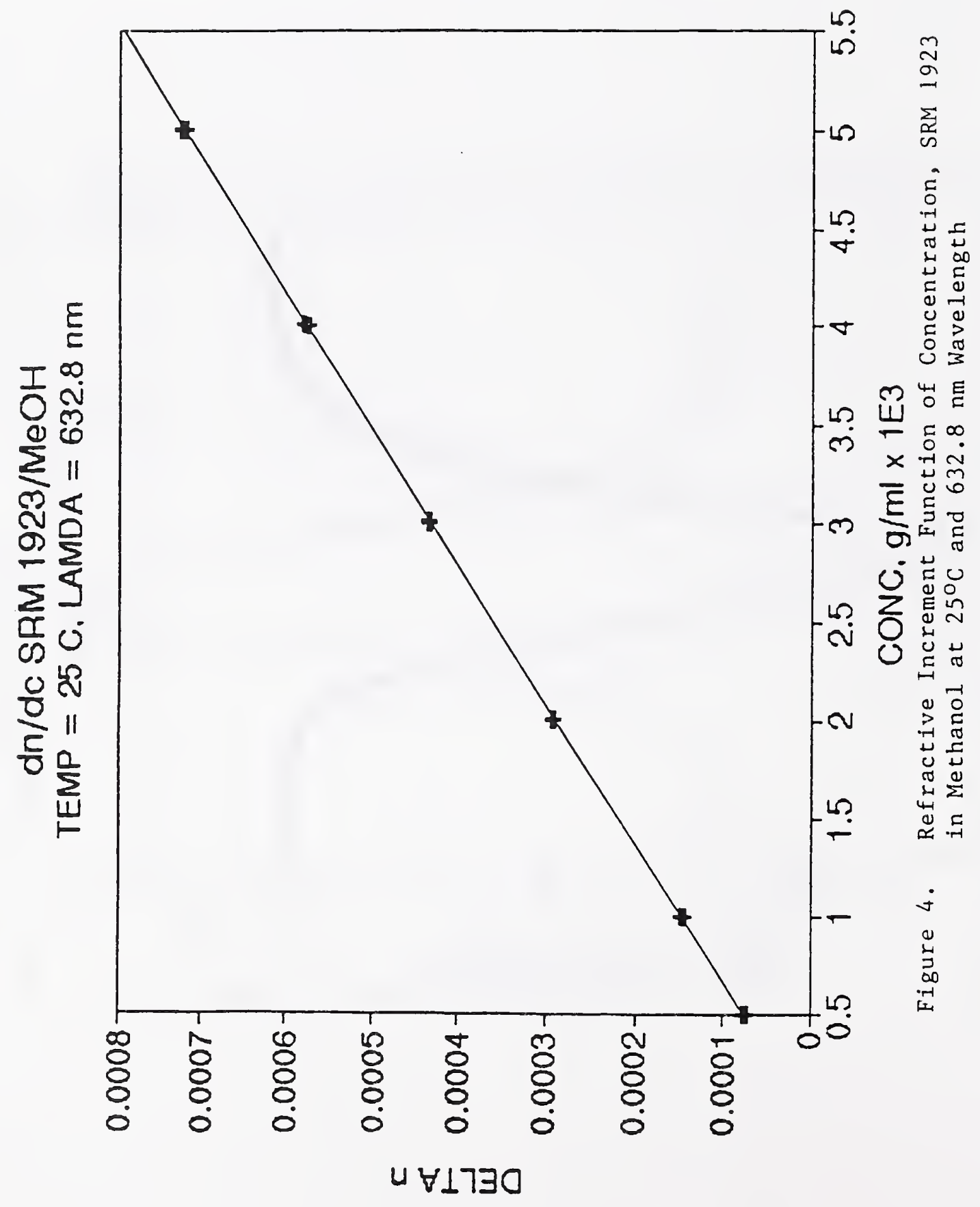




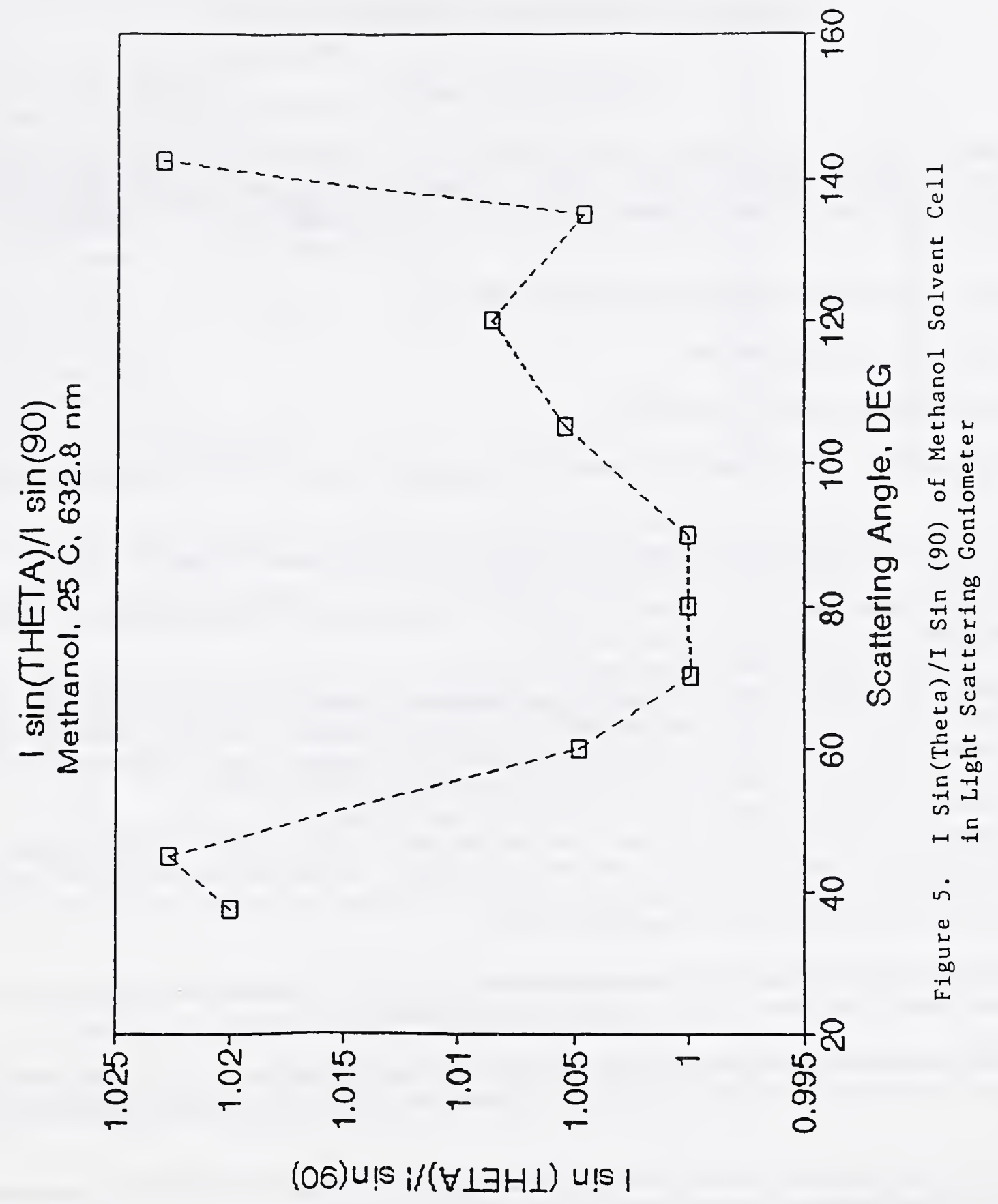




\section{UTrtifirate of Amalysis}

\section{Standard Reference Material 1923}

\section{Poly(ethylene oxide)}

This Standard Reference Material (SRM) is intended primarily for use in calibration and performance evaluation of instruments used to determine molecular weight and molecular weight distribution by size exclusion chromatography (SEC) or gel filtration chromatography. SRM 1923 is supplied in the form of a white powder, and in units of $0.2 \mathrm{~g}$.

This material is certified for weight-average molecular weight $\left(\mathrm{M}_{\mathbf{w}}\right)$ :

$\mathrm{M}_{\mathrm{w}}=26.9 \times 10^{3} \pm 2.2 \times 10^{3} \mathrm{~g} / \mathrm{mole}^{\mathrm{a}}$

${ }^{a}$ Combined expanded uncertainty, $U$ (see Table 1).

The above uncertainty was calculated by a procedure complying with the description in NIST Technical Note 1297 [1].

Source: This poly(ethylene oxide) was prepared by Polymer Labs, Church Stretton, Shropshire, England.

Expiration of Certification: This certificate will be valid for five years from the date of shipment from NIST, when maintained under recommended storage conditions.

Homogeneity and Material Characterization: The homogeneity of the polymer was tested by SEC analysis of solutions in water at $30^{\circ} \mathrm{C}$. The $\mathrm{M}_{w}$ was determined by Rayleigh light scattering. The $M_{w} / M_{n}$ ratio $\left(M_{n}\right.$ is the number average molecular weight) was estimated as $1.06 \mathrm{from}$ the SEC analyses in water. The characterization of this poly(ethylene oxide) by SEC and by light scattering is described in NISTIR 5286 [2].

A high molecular weight peak, distinctly remote from the main peak, occasionally appeared in chromatograms during an aging study of this poly(ethylene oxide) by aqueous SEC. The high molecular weight peak can be removed by heating the solution at $50^{\circ} \mathrm{C}$ for $1 \mathrm{~h}$. In order to avoid degradation, solutions of the standard should be freshly prepared before each SEC calibration.

Storage: SRM 1923 is provided bottled in an environment of dry argon. The polymer sample should be stored in the original bottle tightly closed, under normal laboratory conditions.

The technical coordination leading to certification of this material was provided by C.C. Han, with technical measurement and data interpretation provided by C.M. Guttman and J.R. Maurey, all of the NIST Polymers Division.

Technical and support aspects involved in the preparation, certification, and issuance of this SRM were coordinated through the Standard Reference Materials Program by J.C. Colbert.

Gaithersburg, MD 20899

Thomas E. Gills, Chief

June 10, 1994

Standard Reference Materials Program 
Table 1. Components of Uncertainty in

Weight-Average Molecular Weight of SRM 1923

Source of Uncertainty

Standard deviation of the mean $\mathbf{M}_{\mathbf{w}}{ }^{\mathrm{b}}$

Solvent index of refraction

Calibration of differential refractometer

Differential refractive index

Wavelength of light

Rayleigh ratio of scattering standard

Light polarizers

Ratio of standard scattering to sample scattering

Solvent density

Solute weights and solvent weights

Light reflection

Optical alignment

Refraction correction

Anisotropy of polymer in solution

Truncation of virial expansion

Solute degradation
Degrees of

Freedom

3

5

10 $u_{i}$

g/mole $\times 10^{3}$
Type of

Uncertainty

Combined standard uncertainty: $u_{c}=1.09 \times 10^{3} \mathrm{~g} /$ mole by root-sum-of-squares of $u_{i}[2]$.

Combined expanded uncertainty: $U=2.18 \times 10^{3} \mathrm{~g} / \mathrm{mole}$, obtained by multiplying $u_{c}$ by a coverage factor of $\mathrm{k}=2[1]$.

b. The standard uncertainty of a mean, $u_{i}$, is equated with the standard deviation of the mean when computed from analysis of variance of a statistical population of measurements [1].

c. Type A uncertainties are evaluated by statistical methods [1,2].

d. Type B uncertainties are evaluated by other means $[1,2]$. Degrees of freedom for all Type B uncertainties are infinite [2].

\section{REFERENCES}

[1] Taylor, B.N. and Kuyatt, C.E., Guidelines for Evaluating and Expressing the Uncertainty of NIST Measurement Results, NIST Tech. Note 1297, Jan. 1993.

[2] Guttman, C.M. and Maurey, J.R., Determination of the Weight-Average Molecular Weight of Two Poly(ethylene oxides), SRM 1923 and SRM 1924, NISTIR 5286, 1994. 


\title{
Avational Institute of Standards \& Uprhnalogy
}

\section{Urertifirate of Amalysis}

\section{Standard Reference Material 1924}

\author{
Poly(ethylene oxide)
}

This Standard Reference Material (SRM) is intended primarily for use in calibration and performance evaluation of instruments used to determine molecular weight and molecular weight distribution by size exclusion chromatography (SEC) or gel filtration chromatography. SRM 1924 is supplied in the form of a white porous mat easily sampled by cutting with clean scissors and in units of $0.2 \mathrm{~g}$.

This material is certified for weight-average molecular weight $\left(M_{w}\right)$ :

$M_{w}=120.9 \times 10^{3} \pm 9.0 \times 10^{3} \mathrm{~g} / \mathrm{mole}^{\mathrm{a}}$

${ }^{a}$ Combined expanded uncertainty, U (see Table 1).

The above uncertainty was calculated by a procedure complying with the description in NIST Technical Note 1297 [1].

Source: This poly(ethylene oxide) was prepared by Polymer Labs, Church Stretton, Shropshire, England.

Expiration of Certification: This certificate will be valid for five years from the date of shipment from NIST, when maintained under recommended storage conditions.

Homogeneity and Material Characterization: The homogeneity of the polymer was tested by SEC analysis of solutions in water at $30^{\circ} \mathrm{C}$. The $M_{w}$ was determined by Rayleigh light scattering. The $M_{w} / M_{n}$ ratio $\left(M_{n}\right.$ is the number-average molecular weight) was estimated as 1.04 from the SEC analyses in water. The characterization of this poly(ethylene oxide) by SEC and by light scattering is described in NISTIR 5286 [2].

A high molecular weight peak, distinctly remote from the main peak, occasionally appeared in chromatograms during an aging study of another poly(ethylene oxide) standard by aqueous SEC. The high molecular weight peak can be removed by heating the solution at $50^{\circ} \mathrm{C}$ for $1 \mathrm{~h}$. In order to avoid degradation, solutions of the standard should be freshly prepared before each SEC calibration.

Storage: SRM 1924 is provided bottled in an environment of dry argon. The polymer sample should be stored in the original bottle tightly closed and in a desiccator, under normal laboratory conditions.

The technical coordination leading to certification of this material was provided by C.C. Han, with technical measurement and data interpretation provided by C.M. Guttman and J.R. Maurey all of the NIST Polymers Division.

The technical and support aspects involved in the preparation, certification, and issuance of this SRM were coordinated through the Standard Reference Materials Program by J.C. Colbert.

Gaithersburg, MD 20899

Thomas E. Gills, Chief

June 1, 1994

Standard Reference Materials Program 
Table 1. Components of Uncertainty in Weight-Average Molecular Weight of SRM 1924

\section{Source of Uncertainty}

Standard deviation of the mean $\mathrm{M}_{\mathrm{w}}{ }^{\mathrm{b}}$

Solvent index of refraction

Calibration of differential refractometer

Differential refractive index

Wavelength of light

Rayleigh ratio of scattering standard

Light polarizers

Ratio of standard scattering to sample scattering

Solvent density

Solute weights and solvent weights

Light reflection

Optical alignment

Refraction correction

Anisotropy of polymer in solution

Truncation of virial expansion

Solute degradation
Degrees of

Freedom

\section{3}

5

10

\begin{tabular}{cc}
$u_{i}$ & $\begin{array}{c}\text { Type of } \\
\text { g/mole } \times 10^{3}\end{array}$ \\
\hline
\end{tabular}

0.5

0.06

1.21

0.48

$<0.04$

3.63

0.24

$<0.04$

0.06

0.12

$<0.04$

1.33

0.36

0.12

1.69

0.36
$A^{c}$$$
B^{d}
$$

A

A

B

B

B

B

B

B

B

B

B

B

B

B

Combined standard uncertainty: $u_{c}=4.48 \times 10^{3} \mathrm{~g} /$ mole by root-sum-of-squares of $u_{i}[2]$.

Combined expanded uncertainty: $U=8.97 \times 10^{3} \mathrm{~g} /$ mole, obtained by multiplying $u_{c}$ by a coverage factor of $k=2$ [1].

b. The standard uncertainty of a mean, $\mathrm{u}_{\mathrm{i}}$, is equated with the standard deviation of the mean when computed from analysis of variance of a statistical population of measurements [1].

c. Type A uncertainties are evaluated by statistical methods $[1,2]$.

d. Type B uncertainties are evaluated by other means [1,2]. Degrees of freedom for all Type B uncertainties are infinite [2].

\section{REFERENCES}

[1] Taylor, B.N. and Kuyatt, C.E., Guidelines for Evaluating and Expressing the Uncertainty of NIST Measurement Results, NIST Tech. Note 1297, Jan. 1993.

[2] Guttman, C.M. and Maurey, J.R., Determination of the Weight-Average Molecular Weight of Two Poly(ethylene oxides), SRM 1923 and SRM 1924, NISTIR 5286, 1994. 

